EMBRYARIDDLE
Aeronautical University

SCHOLARLY COMMONS
International Journal of Aviation, Aeronautics, and Aerospace

\title{
High-elevation equatorial catapult-launched RBCC SSTO spaceplane for economic manned access to LEO
}

Nihad E. Daidzic

AAR Aerospace Consulting, LLC, aaraerospace@cs.com

Follow this and additional works at: https://commons.erau.edu/ijaaa

\section{Scholarly Commons Citation}

Daidzic, N. E. (2016). High-elevation equatorial catapult-launched RBCC SSTO spaceplane for economic manned access to LEO. International Journal of Aviation, Aeronautics, and Aerospace, 3(2).

https://doi.org/10.15394/ijaaa.2016.1116

This Article is brought to you for free and open access by the Journals at Scholarly Commons. It has been accepted for inclusion in International Journal of Aviation, Aeronautics, and Aerospace by an authorized administrator of Scholarly Commons. For more information, please contact commons@erau.edu. 
Achieving economical access to Low Earth Orbit (LEO) is one of the central goals in near-space manned missions. A recently retired US Space Transportation System (STS) Space Shuttle required burdensome amounts of manpower to make each launch possible and the cost of one mission was a staggering close to one billion US\$ in 2011. The current cost to get payload in LEO using various launch vehicles ranges between $\$ 20,000$ and $\$ 50,000$ per $\mathrm{kg}$. The prime reason for this hefty cost is in the huge, mostly kinetic, energy requirement to get payload into orbit, expensive infrastructure, strict and complex safety guidelines, and the sheer number of people required to maintain facilities and support operations. The existing chemical-thermodynamic-rocket parallelboosted multi-stage launch vehicles typically carry about $85 \%$ of the entire weight in propellants. Most of the launch vehicle's stages are expendable plus it often contributes to hazardous space-junk (orbiting debris from previous missions) polluting near-space environment.

The primary goal is thus to reduce the launch cost by an-order-of magnitude and make space-missions planning and launching faster which could make commercial space operations affordable and encourage responsible access to space. Another important goal is to have fully reusable horizontal-takeoff horizontal-landing (HTHL) airplane-like Single-Stage-To-Orbit (SSTO) spaceplane which significantly simplifies space missions and reduces overall cost. However, based on the overall best existing liquid cryogenic bi-propellants (Liquid Oxygen or LOX and Liquid Hydrogen or LH2), with the associated best effective specific impulse ( $\mathrm{I}_{\mathrm{SP}}$ ) of 450-460 seconds in vacuum, the pure rocketmode SSTO concept is highly marginal (about $90 \%$ mass/weight in propellants alone plus 8-9\% for inert/structural mass) and essentially needs separable, and desirably reusable, booster stages for any sensible payload fraction. Such was indeed the case of the recently-retired STS Space Shuttle Orbiter as seen here in Figure 1 (Photo courtesy of NASA-MSFC), Russian "Buran", and European Space Agency's (ESA) "Hermes" designs (Zaehringer, 2004). Notable historical designs is 1958 USAF's X-20 "Dyna-Soar" (Dynamic Soarer) lifting-body suborbital aerospace plane vehicle which was conceptually elevated to an orbital vehicle, but never flew (Zaehringer, 2004). A recent example of ultimately unfinished SSTO concept was Lockheed Martin's Venture Star (NASA's designation X-33) design cancelled in 2001, even though it implemented more efficient linear aerospike nozzles, lifting-body aerodynamics, and lighter composite-based fuel tanks (Daidzic, 2011; Zaehringer, 2004). SSTO is indeed a very marginal concept.

An intermediate solution is to have Two-Stage-To-Orbit (TSTO) which certainly makes LEO missions technically less challenging, but increases the cost, 
complexity, planning, and execution. Any air-launch of orbital vehicles is indeed a TSTO (or more stages) concept. Many designs have been proposed in the past 50 years or so. For example, the European concept which was never designed and subsequently canceled in 1994, was Sänger II aerospace plane (Heiser et al., 1994). It consisted of a $1^{\text {st }}$ stage Turbine-Based Combined-Cycle (TBCC), turboramjet hypersonic European Hypersonic Transport Vehicle (EHTV) and the $2^{\text {nd }}$ stage being the conventional chemical-rocket powered Hypersonic Orbital Upper Stage (Horus) (Daidzic, 2011; Zaehringer, 2004).

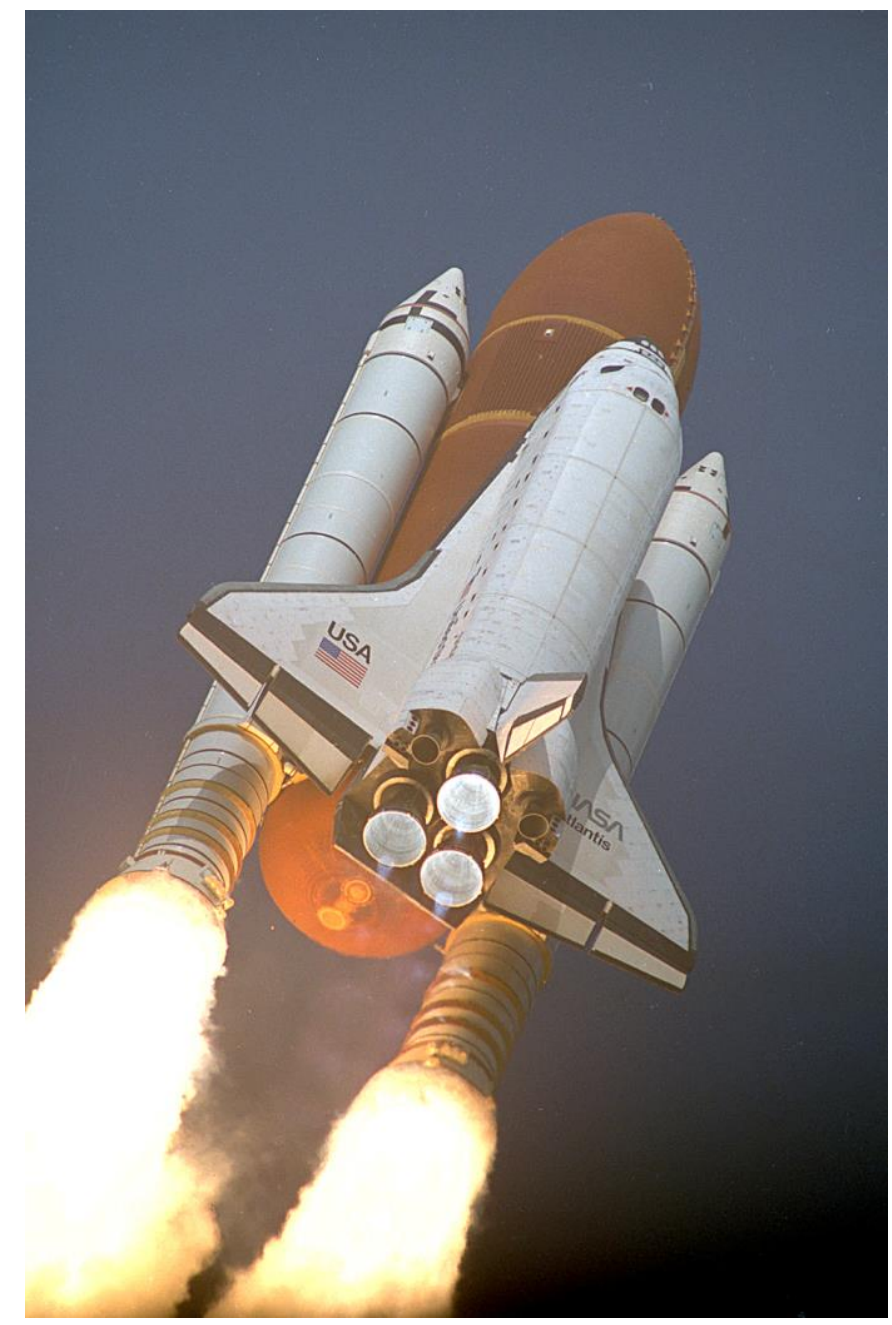

Figure 1. After roll maneuver and short vertical ascent, the mighty STS Space Shuttle starts a gravity turn (GT). In addition to three main engines, the two OMS engines are also clearly visible. Image courtesy of NASA/Marshall Space Flight center (NASA-MSFC). 
The main technical problems facing economic SSTO designs are in finding High-Energy Density Materials (HEDM) fuels and efficient Rocket-Based Combined-Cycle (RBCC) propulsion systems that combine various air-breathing and rocket modes. For sub-orbital atmospheric flights a TBCC counterpart may be used and indeed has a flight heritage, such as P\&W J58 in SR-71 (Daidzic, 2010, 2011; Kloesel et al., 2011).

Difficult problems with scramjet propulsion (supersonic combustion) are seriously hampering dreams of Mach 10 hypersonic flight. For that reason, we stayed away from incorporating uncertain scramjet propulsion designs in the concept presented. LH2 is used as a fuel of choice for achieving higher Mach numbers in ramjet (subsonic combustion) modes rather than hydrocarbon Rocket Propellant (RP-1) fuel. While ramjets have flight heritage and are reasonably effective propulsive devices, scramjets are still in its infancy with no certainty as to when they will become reliable enough for commercial use. No attempt for detailed combustion, thermal, and compressible aerodynamics ramjet calculations was made due to space constraints.

Therefore, we propose here a multi-purpose SSTO space-taxi (or space Cessna 172) concept with strap-on reusable hybrid-rocket boosters (HRB) for 120 seconds launch-assist and advanced RBCC ramrocket engine consisting of combined ramjet- and (ducted) rocket-mode. A powerful magnetic-levitation (MAGLEV) catapult (sled) serves as a zero-stage. The catapult-launch could deliver sustained $2.0 \mathrm{~g}$ acceleration to $300-310 \mathrm{~m} / \mathrm{s}(\mathrm{M}=0.9$ at $5 \mathrm{~km}$ ISA elevation) The single RBCC sustainer and the twin $120 \mathrm{~s}$ HRBs accelerators take the spaceplane into a 300-km LEO in about 8 minutes. Controlled acceleration is maintained until the Main-Engine-Cut-Out (MECO) and orbital injection.

The main idea and purpose of this research article is to explore technical and economic challenges and opportunities, and study feasibility of such smallpayload manned SSTO spaceplane designs. A promising, yet still quite marginal, design utilizes a single RBCC ramrocket sustainer engine using cryogenic Liquid Rocket Engine (LRE) with LH2+LOX bi-propellants and supported, in transatmospheric ascent, by reusable strap-on parallel-stage twin HRB with oxidizer LOX and solid fuel Hydroxil-Terminated PolyButadiene (HTPB). When launched by catapult-rail system from high-elevation equatorial sites it is hoped that economical short-duration LEOs can be achieved and the launch cost reduced by an order-of-magnitude compared to existing systems. Unlike the STS Space Shuttle orbiter design with external LOX/LH2 tanks, all propellants are carried in a spaceplane. Astronauts could spend from few hours up to several days by using ISS and designed shelters in space. Short duration taxi-trips can be conducted. 
The originality of this proposal stems from the inclusion of several highelevation equatorial subsonic catapult-launch facilities with associated runways for dead-stick or limited power-on landings. Equatorial orbit is available by default with minimum propellant expenditure. Arbitrary orbital inclinations are possible, but retrograde (indirect) orbits become increasingly prohibitive. The benefit of the high-altitude (elevation) equatorial launch sites is also in locally reduced terrestrial acceleration (apart from possible gravitational anomalies), thicker radius of oblate-Earth and thus shorter actual (orthometric) distance to LEO. Additionally, high equatorial elevations offer reduced air densities, lower aerodynamic drag and gravity loss plus maximizes easterly inertial orbital speed boost enabling frequent launch windows for arbitrary direct orbital inclinations.

None of before mentioned individual contributions makes much dent in the extraordinary mission launch energy and cost requirements, but all combined, make an otherwise marginal, SSTO concepts just maybe economically and technically feasible with the existing and/or near-future technologies. It is estimated that minimum of about $500-600 \mathrm{~m} / \mathrm{s}$ launch energy is saved on average per mission compared to other existing spaceports and launch systems. While Boeing's Sea Launch platform can be positioned at equatorial latitudes, the SeaLevel (SL) altitude/elevation and its size restricts the use of horizontal launches (and landings). Air launches are by definition at least TSTO concepts and carry their own problems. Use of RBCC propulsion mode further increases missionaverage specific impulse requiring less of the on-board oxidizer. There are many other details and issues that we considered, but due to space restriction they could not have been properly addressed here.

\section{Literature Review}

We are only addressing references that are directly relevant to our research work. It is very possible that similar ideas of equatorial high-altitude launches was discussed earlier somewhere, but no publically available source was found that introduces the ideas presented here. This work has been created independently based on the work and author's own experience and expertise over the past 27 years.

Every equation and expression used in this study has been also independently derived here and then cross-checked using various references. Many, but of course not all, expert books and well-known classics in orbital and celestial mechanics were consulted and checked for necessary computations, such as, Bate et al. (1971), Danby (1962), Deutsch (1963), Fitzpatrick (2012), Moulton (1970), Plummer (1960), Sellers (2005), Thomson (1986), and Weiland (2010). 
For space vehicle and attitude dynamics many books were used including Ashley (1992), Ball and Osborne (1967), Deutsch (1963), Hughes (2004), Tewari (2007), and Thomson (1986). Transatmospheric rocket and missile flight dynamics (stability and control) is covered in the books by Ashley (1992), Ball and Osborne (1967), Etkin (1959, 2000), Kolk (1961) and Tewari (2007). Reentry aerodynamics, heat transfer and deceleration problems are covered in Chapman (1958), Regan and Anandakrishnan (1993), Sellers (2005), Tewari (2007), Vinh (1993) and Weiland (2010). Many classical texts on rocket propulsion were used, such as, Goddard (2002), Hill and Peterson (1992), Humble et al. (1995), Huzel and Hwang (1992), Oates (1997), Sellers (2005), Sutton and Biblarz (2001), and Sutton (2006). No reference list can ever be fully complete.

Foster (1989) suggested the use of RBCC SSTO vehicle and performed trajectory optimization study with Mach 15 pitch-optimized trajectory for intermediate orbital altitude access followed by the Hohmann transfer and insertion/circularization to achieve $100 \mathrm{NM}(186 \mathrm{~km})$ circular polar orbit. Chojnacki (1992) present executive summary of workshop on RBCC propulsion held in Marshall Space Flight Center (MSFC). Propulsion systems, background of RBCC, alternatives, vehicle integration, ground and flight testing, and operational considerations were discussed among other things. Many useful conclusions and recommendations were offered. Olds and Walberg (1993) discuss multidisciplinary design of RBCC SSTO launch vehicles using parametric Taguchi methods. The authors reviewed some of the older RBCC concepts which included air-augmented rockets, ejector and supercharged ejector ramjet (SERJ), and the scramLACE (scramjet Liquid Air Cycle Engine). The mission averaged specific impulse using various RBCC modes were in the 630-780 seconds range. The main goal of the authors was to reintroduce and revisit the promising RBCC propulsion systems into SSTO concepts. Heiser et al. (1994) provides excellent one-dimensional thermodynamic and performance analysis of ramjets, scramjets and ejector ramjets, which demonstrates the feasibility of using such propulsion systems in transatmospheric hypersonic flights. Thrust augmentation in ejectorramjets was studied and shown that it can be significant (range 1.6 to 2.2). The authors also provide extensive thermodynamic analysis of various TBCC and RBCC systems. This book is a valuable reference in many aspects of combined airbreathing and vacuum propulsion. Humble et al. (1995) discuss air-augmented rockets and other basic RBCC systems in a chapter on advanced propulsion systems. In addition to airbreathing RBCC modes another possibility to increase average specific impulse of traditional rocket engines is to design High-EnergyDensity Materials (HEDM) fuels. However, such fuels are extremely unstable (e.g., free radicals). Smith et al. (1998) in NASA's TM report focus on all-rocket mode of an RBCC propulsion system. Rocket mode was shown to be a critical 
factor in the overall RBCC performance. Their main finding was that to increase the rocket-mode performance, rocket area ratio must be maximized. Manski et al. (1998) discuss thermodynamic cycles for Earth-to-orbit propulsion. As per authors, the technology levels for single-mode cycle engines for future SSTO have already been achieved by Space Shuttle Main Engine (SSME) and RD-O120 engines. In an thorough study of performance concentrating on turbopump-feed propulsion cycles, the authors claimed that a staged combustion cycle with a single fuel-rich preburner producing a (thrust) chamber pressure of only 200 bar (2.0 MPa) would be sufficient to power an SSTO to deliver $16,500 \mathrm{~kg}$ tons into LEO. Olds and Bellini (1998) showed results of the conceptual design study in support of NASA's highly-reusable space-transportation initiative. An RBCC SSTO Argus vehicle with Maglifter (MAGLEV sled launch assist) used to accelerate $597,250 \mathrm{lbf}$ vehicle to $800 \mathrm{fps}(244 \mathrm{~m} / \mathrm{s})$ with the payload capability of 20,000 lbf (about 9 metric tons) was proposed. The authors envisioned building three reusable RBCC SSTO Argus vehicles flying a total of 159 flights per year at a cost of $\$ 169 / \mathrm{lb}(\$ 372 / \mathrm{kg})$.

Czysz and Richards (1999) discuss the benefits of changing the propulsion cycle on then X-33 Venture Star SSTO project. With a LACE propulsion cycle Venture Star could increase payload weight in a smaller vehicle enabling more frequent and cheaper space missions. Bertin and Cummings (2003) provided an exhaustive review of hypersonic research over the (then) past 50 years and have identified advances so far and key known technologies and problems that need to be addressed in the future. According to the authors, the hypersonic environment is very harsh, unforgiving, and full of surprises and unknown unknowns, typically always learned in the hard way during flight tests. A historical account and description of various LREs is given in Sutton (2006). Kanda and Kudo (2003) and Kanda et al. (2007) present conceptual study on ejector ramjet ramrocket. From their analytical study it was found that that thrust augmentation can be significant in combined modes for supersonic Mach numbers, but is relatively small at low subsonic speeds. Simulation of RBCC engine operation an SSTO spaceplane flight proved the analytical results. Luetke et al. (2007) performed numerical optimization of mass flow ratio of the scramjet inlet to the rocket jet and the resultant flow field in the engine path for the RBCC SSTO concept.

Balepin (2008) discusses high-speed aircraft and space-launch vehicle synergetic cycles propulsion systems employing thrust enhancement of turbojet engines (TBCC) and RBCC concepts. His study covers four TBCC accelerators, such as, ATREX (expander air turbo ramjet), ATRDC (deeply cooled air turbo rocket), MIPCC (mass injection pre-compressor cooling), and rocket augmented turbine. The RBCC accelerators include KLIN cycle (thermally integrated deeply 
cooled turbojet and rocket engine) and AspiRE (aspirating rocket engine), as well as scramjets and rocket engines. Many concepts must use Liquid Hydrogen (LH2) while others can use hydrocarbon fuels. Some of the concepts may be applicable to SSTO designs, and some could be used as the first stages in TSTO. Haidn (2008) discusses some basic rocket propulsion concepts and performance figures and remarks on possible future improvements in rocket engine designs. These would include laser-based ignition system, cheaper injection system without significantly diminished performance, advanced nozzle designs including the dual-bell nozzles, etc. Tsohas et al. (2009) present current and ongoing developments on a Purdue University 900-lbf $\mathrm{H}_{2} \mathrm{O}_{2} /$ LDPE hybrid-rocket technology demonstrator. Their hybrid rocket (liquid oxidizer Hydrogen Peroxide and solid fuel low-density PolyEthylene) is being designed for ultimately reaching $100+\mathrm{km}$ suborbital flights. Many successful launches were performed in addition to ground testing. Daidzic (2010) presented some TBCC and RBCC propulsion concepts that could be used in future suborbital and orbital business aviation and space tourism. An emphasis was also given to hypersonic research and atmospheric re-entry. An idea of high-altitude equatorial RBCC spaceplane launches was presented. Kloesel et al. (2011) describe development of engine models and ascent trajectories, which demonstrate that already existing systems, are at least, nominally capable of providing airbreathing space access for practical payload sizes. According to authors, the TBCC have been already flight proven, and many RBCC propulsion systems have been fully ground-tested and merely are awaiting flight testing too bring them to the next level of technology readiness. Kothari et al. (2011) performed extensive study of RBCC hypersonic vehicle of TSTO design for orbital access. Also vehicle reentry performance was analyzed along with cost analysis and exploring the potential for commercial use. Daidzic (2011) discussed, in a popular aerospace industry article, RBCC propulsion concepts in conjunction with SSTO spaceplanes. The old airaugmented (ducted) rocket idea was revisited in addition to providing MAGLEV catapult-rail launch system from suitable geographic locations for a 200,000 lb spaceplane which is an order-of-magnitude larger then proposed here. Ahuja and Hartfield (2012) performed preliminary design level optimization trade study of integrated air-breathing ramjet/scramjet propulsive assist for a LOX/RP-1 rocketpowered vertical launch vehicle. There is no reason to discard the RBCC concepts for trans-atmospheric ascents for deep-space manned (or unmanned) missions. Any future lunar or (inter-)planetary mission can utilize RBCC concepts to reduce the cost of and enable putting significant payload in Earth's parking orbit first (Daidzic, 2014). Recently, Daidzic (2016) discussed the energy and cost savings of a proposed 200,000 lbf heavy RBCC SSTO spaceplane for short-duration LEO access. Rail-catapult launch from several high-elevation equatorial locations was also suggested for the first time to the best of our knowledge. 


\section{Mathematical Models and Methodology}

The ideal or Tsiolkovsky's rocket equation in integral form expressing the velocity (energy) budget (Ashley, 1992; Ball and Osborne, 1967; Farokhi, 2009; Goddard, 2002; Hill and Peterson, 1992; Humble et al., 1995; Lee, 2014; Oates, 1997; Sellers, 2005; Shevell, 1983; Sutton and Biblarz, 2001; Tewari, 2007; Thomson, 1986; Ward, 2010), yields:

$$
v_{f}-v_{i}=\Delta v=v_{\text {eff }} \cdot \ln (m r) \quad m r=\frac{m_{i}}{m_{f}} \geq 1
$$

Velocity increments $\Delta v$ (delta-v) are vector additive and describe energy requirements and propellants needed to achieve orbits. This innocently looking equation actually reveals harsh realities of space flight. The amount of kinetic energy needed to achieve LEO is staggering. The effective one-dimensional exhaust velocity $v_{\text {eff }}$ is based on the nozzle cross-section averaged true exit velocity of the propellant mass and the correction for the pressure thrust at the nozzle exit:

$$
C=v_{\text {eff }}=v_{e}+\frac{A_{e}}{\dot{m}_{\text {prop }}}\left(p_{e}-p_{a}\right)=I_{S P} \cdot g_{0} \quad\left(\dot{m}_{\text {prop }}=-\frac{d m}{d t}\right)
$$

The specific impulse is defined as:

$$
I_{S P} \equiv \frac{T}{\dot{W}_{\text {prop }}}=\frac{T}{\dot{m}_{\text {prop }} \cdot g_{0}}=\frac{1}{T S F C}=\frac{C}{g_{0}}=\frac{c^{*} C_{F}}{g_{0}} \quad[\mathrm{sec}]
$$

If TSFC is given in (lbf/hr) of fuel per (lbf) of thrust then, $I_{S P}=3600 / T S F C$.

The fundamental forces acting on a rocket are thrust (T) and weight (W). We can add to that aerodynamic component forces: lift (L) and drag (D) during transatmospheric flight. Of course, pitching, rolling and yawing torques are present as well which must be controlled. From the Newton's $2^{\text {nd }}$ law or the law of conservation of linear momentum, one obtains ordinary differential equation (ODE) of motion along the flight trajectory:

$d v=-C \frac{d m}{m}-\frac{D}{m} d t-g \sin \theta d t$ 
The final rocket velocity is also called the burnout velocity. Instead of velocity vector we will be only speaking about the speed tangential to the trajectory (flight-path coordinates). A trajectory can have an arbitrary inclination angle $\gamma$ in relationship to flat-Earth approximation (or local horizontal). For orbital insertion or when $\gamma=0$ (rocket is parallel to local horizontal), the burnout speed is the orbital speed. Thus, the mission required burnout speed can be expressed as:

$$
\begin{aligned}
& \int_{v_{i}}^{v_{f}} d v=v_{f}-v_{i}=\Delta v \Rightarrow \\
& v_{f}=v_{b}=v_{i}+\int_{m_{b}}^{m_{i}} C \frac{d m}{m}-\int_{t_{i}}^{t_{b}} \frac{D}{m} d t-\int_{t_{i}}^{t_{b}} g \cdot \sin \theta d t=v_{i}+\Delta v_{\text {eff }}-\Delta v_{\text {drag }}-\Delta v_{\text {gravity }}
\end{aligned}
$$

The initial velocity is normally zero in the case of the first stage, but since catapult-launch is used it will actually be larger than zero. Further, we have:

$$
\Delta v_{\text {drag }}=\int_{t_{i}}^{t_{b}} \frac{D(t)}{m(t)} d t \quad \Delta v_{\text {gravity }}=\int_{t_{i}}^{t_{b}} g(h) \sin \theta(t) d t=g_{0} \int_{t_{i}}^{t_{b}}\left[\frac{R_{e}}{R_{e}+h(t)}\right]^{2} \sin \theta(t) d t
$$

Traditionally, these terms are called losses, which is true for aerodynamic drag and steering losses, but not really for gravity which is conservative force. The effective speed and the required propellant must account for these losses if a desired burnout velocity is to be reached. However, for prograde (direct) orbits, a rocket can take advantage of Earth's rotation and it gets automatic inertial-speed boost depending on the latitude of the launch site and the orbit inclination (launch azimuth). The spaceplane stability (balancing broomstick problem), guidance, and control issues as well as steering modelling and simulation are not addressed in this feasibility study. It is not possible to obtain the closed-form solution of Equation (5). Thus, one must resort to numerical integration. Multi-staging and trajectory optimizations are crucial in finding most cost-effective designs and solutions (Ashley, 1992; Ball and Osborne, 1976; Hill and Peterson, 1992; Oates, 1997; Tewari, 2007; Thomson, 1986). These are extremely difficult problems, which cannot be addressed here. The initial and final single-stage spaceplane masses are:

$$
m_{i}=m_{P A Y}+m_{s}+m_{\text {prop }} \quad m_{f}=m_{i}-m_{\text {prop }}=m_{P A Y}+m_{s}
$$


Here, $m_{i}$ stands for the initial total (launch) mass (GLOW - Gross Lift-Off Weight) and $m_{f}$ stands for the final (burnout) mass after all the propellant is depleted and all what is left is payload and inert structure. Specifically, $m_{s}$ is the inert or structure mass, $m_{\text {prop }}$ is time-dependent propellant mass, and $m_{P A Y}$ is the payload mass.

The rocket propulsive efficiency is a ratio of useful propulsive power used to thrust the vehicle and the total power invested which also includes power lost in exhaust jet (Farokhi, 2009; Sutton and Biblarz, 2001):

$\eta_{p}=\frac{P_{\text {out }}}{P_{\text {in }}}=\frac{T v}{T v+\frac{\dot{m}_{\text {prop }}(C-v)^{2}}{2}}=\frac{2(v / C)}{1+(v / C)^{2}}$

The useful part of the input power/energy, i.e., output, goes into accelerating the rocket. The input power is the sum of the power necessary to accelerate the vehicle and the power lost in the exhaust jet. So the maximum propulsive efficiency is achieved when rocket speed is equal to the speed of exhaust gasses, $v=C$. Having the vehicle speed higher or lower than the exhaust gasses $(v>C$ or $v<C)$ results in reduced propulsive efficiencies. Although rocket nozzles are very efficient in converting high-pressure and high-temperature combustion gases into thrust some heat is lost through exhaust. There are also losses connected with the cycle efficiency.

\section{Spaceplane design}

The SSTO spaceplane (also known as spaceplane here) is designed for the crew of two and some additional payload (mini satellites of up to $100 \mathrm{~kg}$ ). Alternatively, there could be one pilot and up to $200 \mathrm{~kg}$ satellite (or other payload). Spaceplane can also operate autonomously without the crew for about $300-\mathrm{kg}$ payload delivery. A windowless spaceplane is designed to endure re-entry thermal and deceleration stresses and has simple landing gear system designed for the landing weight of about 4,500 lb instead of for GLOW=24,000 lb. The basic dry structural weight is about 1,700 lb. All pump-feed fuel liquid propellant system (sustainer and OMS/RCS propellant tanks, LH2/LOX turbopumps, turbine, plumbing, and control) weigh about $500 \mathrm{lb}$. All spaceplane systems (electric, environmental/life-support, flight control, navigation, communication, etc.) about $800 \mathrm{lb}$. The entire spaceplane without RBCC and OMS/RCS engines/thrusters thus weighs only about 3,000 lb. Such design is going to be very hard to achieve and would have to incorporate most modern light-weight (carbonbased) composite materials. The lifting-body spaceplane will be about 9-10 m 
long with integrated highly swept delta-wings (4-5 m wingspan). Ablative and radiation cooling of the structure is used on gliding re-entry. Spaceplane weight breakdown and aerospace propulsion systems weights and thrust are given in Table 1 . It will be very difficult to achieve desired low $C_{D}$ with strapped-on HRB's. Transatmospheric trajectory optimization is crucial task in minimizing propellant consumption.

\section{RBCC Propulsion system}

The $740 \mathrm{lb}(336 \mathrm{~kg}$ ) heavy RBCC ramrocket (air-augmented rocket or ejector rocket) accelerator works in airbreathing ramjet-only, rocket-only, and combined ramrocket modes. We avoided turbojet mode as turbomachinery (compressor/turbine spools) is heavy. The RBCC engines bridge the gap between the atmospheric and rocket engines in terms of dry- and wet-weight (see Figure 2). The integrated inlet is of variable geometry (VGI) allowing for subsonic and supersonic inflow and can be fully closed for rocket-only mode. This is the heaviest and the most sensitive part of the RBCC engine. The nozzle is also of variable geometry. The $\mathrm{LH} 2$ fuel air-breathing ramjet mode provides up to 15,000 lbf of thrust (T/W=20.3:1) with average TSFC of about $2 \mathrm{lbf} / \mathrm{hr} / \mathrm{lbf}$ (Isp=1,800 s). The LH2/LOX rocket-only mode with inlet doors fully closed provides up to $25,000 \mathrm{lbf}$ of thrust $\left(\mathrm{T} / \mathrm{W}=33.8: 1\right.$ ) with average $\mathrm{I}_{\mathrm{SP}}=455$ seconds (TSFC is about 8 $\mathrm{lbf} / \mathrm{hr} / \mathrm{lbf}$ ) and nozzle optimized for low air pressure and large expansion ratio $\left(\varepsilon=A_{e} / A_{t}>1\right)$.

Table 1

RBCC SSTO spaceplane weight and thrust breakdown

\begin{tabular}{lcc}
\hline & Weight $[\mathrm{lb} / \mathrm{kg}]$ & Max thrust rating [lb] \\
\hline Basic dry structure \& systems & $3,000 / 1,364$ & \\
RBCC engine & $740 / 336$ & $26,000 / 25,000 / 15,000$ \\
LH2+LOX bi-propellant & $13,100 / 5,955$ & \\
Payload (incl. crew) & $660 / 300$ & \\
Hybrid rocket boosters (120 s) & $6,000 / 2,727$ & $22,000(2 \times 11,000)$ \\
OMS/RCS engines (incl. fuel) & $500 / 227$ & $600 /(40 \times 16)$ \\
\hline TOTAL & $24,000 / 10,909$ & \\
\hline
\end{tabular}

A schematic drawing of RBCC ramrocket is shown in Figure 3. Engine trust can be modulated by throttling it from about 50\% to 100\%. The RBCC mode provides up to 26,000 $\mathrm{lbf}$ of thrust (T/W=35:1) at speeds up to Mach 7 at which ramjet-mode becomes inefficient and subsonic combustion unusable. Above local 
Mach 7 (about 2,250 m/s), only rocket mode is possible with the VGI fully closed. Ideal thrust from an $\mathrm{RBCC}$ ramrocket can be written generally as:

$$
T_{R B C C}=\underbrace{\dot{m}_{A I R}\left[(1+f) v_{e}-v_{i n}\right]}_{\text {airbreathing thrust }}+\underbrace{\left(p_{e}-p_{a}\right) A_{e}}_{\text {pressurethrust }}+\underbrace{\dot{m}_{P R O P} c^{*} C_{F}}_{\text {rocket thrust }}=\dot{m}_{P R O P} \bar{I}_{S P}^{R B C C}(t) g_{0}
$$

Here, $f=\dot{m}_{f} / \dot{m}_{A I R}$ is airbreathing-mode fuel-air ratio (typically around stoichiometric $1: 15$ or 0.067 by mass/weight for most hydrocarbon fuels). The ideal rocket thrust can be expressed now as:

$$
T_{\text {rocket }}=\dot{m}_{P R O P} \cdot C=\dot{m}_{P R O P} \cdot c^{*} \cdot C_{F}=\dot{m}_{P R O P} \cdot I_{S P} \cdot g_{0}
$$

The characteristic combustion chamber speed $c^{*}$ for LH2/LOX bipropellant combination is typically about 2,300-2,400 $\mathrm{m} / \mathrm{s}$, while the thrust coefficient $\mathrm{C}_{\mathrm{F}}$ depends strongly on the local atmospheric, combustion chamber, and nozzle exit pressures. Typical values for various systems are presented in Table 2.

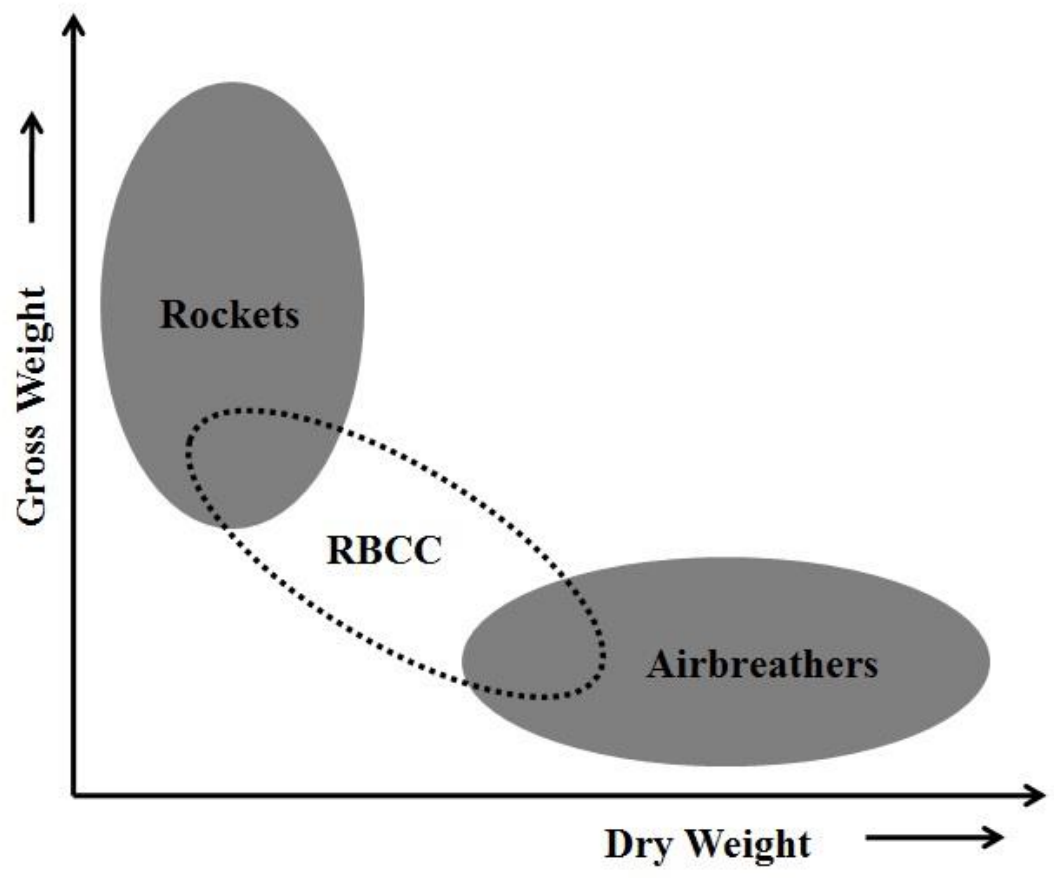

Figure 2. RBCC engines bridge the gap between the atmospheric- and rocketpropulsion systems. Adopted from Olds and Walberg (1993). 
Values of ISP for hydrocarbon fuels and LH2 for turbojet, ramjet, scramjet, and conventional chemical (thermodynamic) rocket engines are shown in Figure 4. Rocket engines have ISP independent of speed. However, atmospheric engines (turbojet, ramjet, scramjet) will have IsP (and TSFC) dependent on the flight speed and the propellants used. Higher specific impulses and speeds can be achieved using LH2 instead of familiar rocket hydrocarbon fuels (e.g., RP-1).

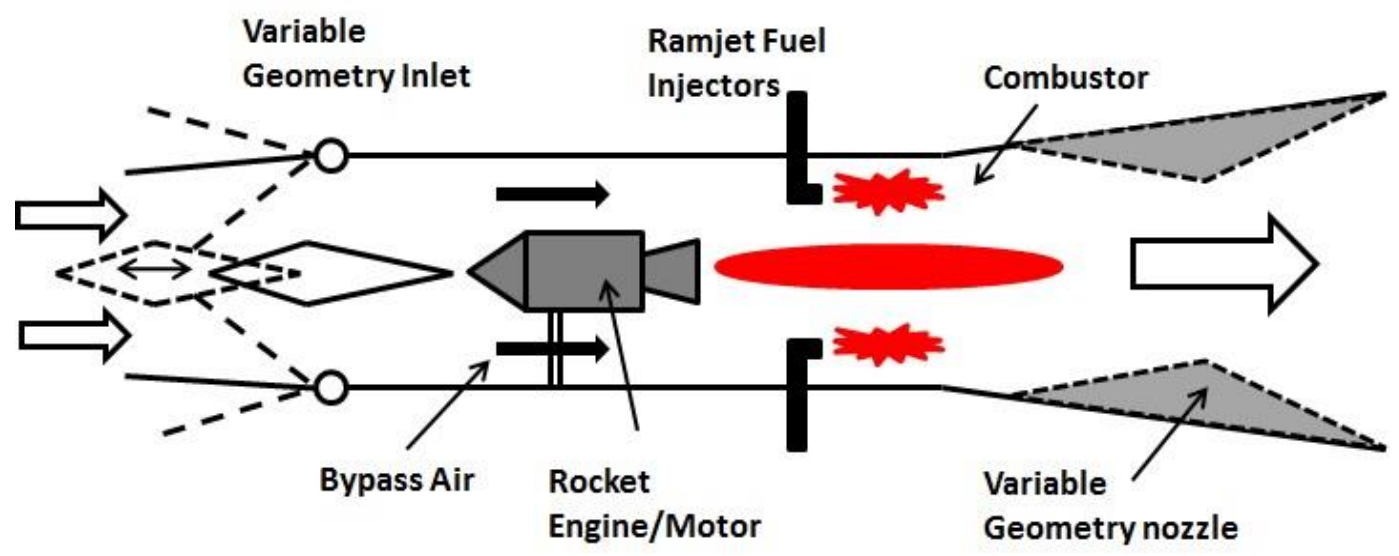

Figure 3. Schematic of air-augmented ramrocket or ejector air-rocket with variable geometry subsonic/supersonic inlet (VGI) and nozzle. Not to scale.

Table 2

Typical values of characteristic rocket engine properties (Haidn, 2008)

\begin{tabular}{cccccccc}
\hline $\mathrm{T}_{0}[\mathrm{~K}]$ & $\mathrm{p}_{0}[\mathrm{MPa}]$ & $\begin{array}{c}\mathrm{M} \\
{[\mathrm{kmol} / \mathrm{kg}]}\end{array}$ & $\mathrm{c}^{*}[\mathrm{~m} / \mathrm{s}]$ & $\mathrm{C}_{\mathrm{F}}[-]$ & $\gamma[-]$ & $\varepsilon[-]$ & $\mathrm{I}_{\mathrm{SP}}[\mathrm{s}]$ \\
\hline $\begin{array}{c}2,000- \\
3,900\end{array}$ & $1-26$ & $2-30$ & $\begin{array}{c}900- \\
2,500\end{array}$ & $1.3-2.9$ & $1.1-1.6$ & $15-280$ & $150-480$ \\
\hline
\end{tabular}

In a combined (air-augmented ejector-jet rocket) mode the RBCC produces maximum of 26,000 $\mathrm{lbf}$ of thrust in lower altitudes. Maximum thrust, TSFC, specific impulse (ISP), and the maximum fuel consumption (FC) for RBCC engine and hybrid motor/booster are summarized in Table 3. Up to 47,000 lbf are available for transatmospheric ascent.

More details on rocket-thrust computations are given in Appendix A. The change of thrust coefficient with the propellant's isentropic ratio and the parametric pressure ratios is calculated and depicted in Figure 5 (see Appendix A 
for computational details). The simulation of atmospheric air-breathing ascent and vacuum rocket propulsion ascent were performed separately and then stitched together. Limited trajectory optimization was performed by repeated simulations for different initial conditions.

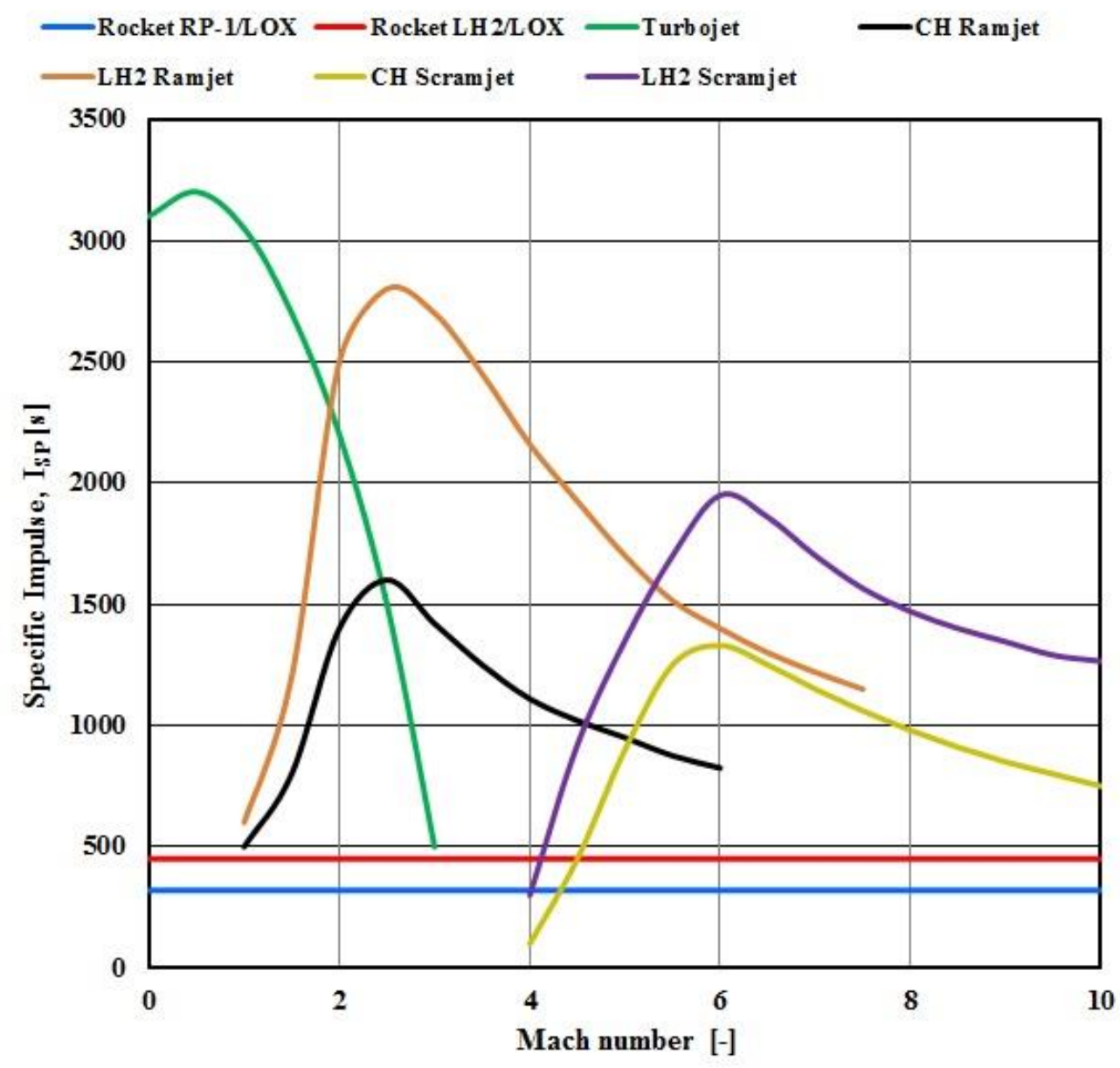

Figure 4. Specific impulse of various propulsive systems using different propellants.

We can also find the ideal expansion ratio for the condition in which nozzle operates. The computed results of optimum nozzle expansion ratios (Appendix A) are summarized in Figure 6. The final expansion ratio will be chosen to optimize between thrust produced and large expansion-ratio nozzle drag. The rocket-only mode is engaged above $120 \mathrm{~km}$ where very little back- 
pressure exists. The correlation between the expansion ratio and combustion chamber pressure does not exist for space engines (Humble et al., 1995).

Table 3

Propulsion mode characteristics

\begin{tabular}{lccccc}
\hline $\begin{array}{c}\text { Propulsion Mode } \\
\text { (650 lb RBCC) }\end{array}$ & $\begin{array}{c}\text { Max } \\
\text { Thrust }[\mathrm{lb}]\end{array}$ & $\begin{array}{c}\text { TSFC } \\
{[\mathrm{lb} / \mathrm{hr} / \mathrm{lb}]}\end{array}$ & $\begin{array}{c}\text { ISP } \\
{[\mathrm{s}]}\end{array}$ & $\begin{array}{c}\text { T/W } \\
{[-]}\end{array}$ & $\begin{array}{c}\mathrm{FC}_{\max } \\
{[\mathrm{lb} / \mathrm{s}]}\end{array}$ \\
\hline RAMJET (atm.) & 15,000 & 2.0 & 1,800 & $20.27: 1$ & 8.333 \\
ROCKET (vac.) & 25,000 & 7.9 & 455 & $33.78: 1$ & 54.861 \\
RBCC (atm.) & 26,000 & 5.0 & 720 & $35.14: 1$ & 35.111 \\
HRB $(2 \times 3,000,1 \mathrm{~b})$ & $2 \times 11,000$ & 10.0 & 360 & $3.67: 1$ & 61.111 \\
\hline
\end{tabular}

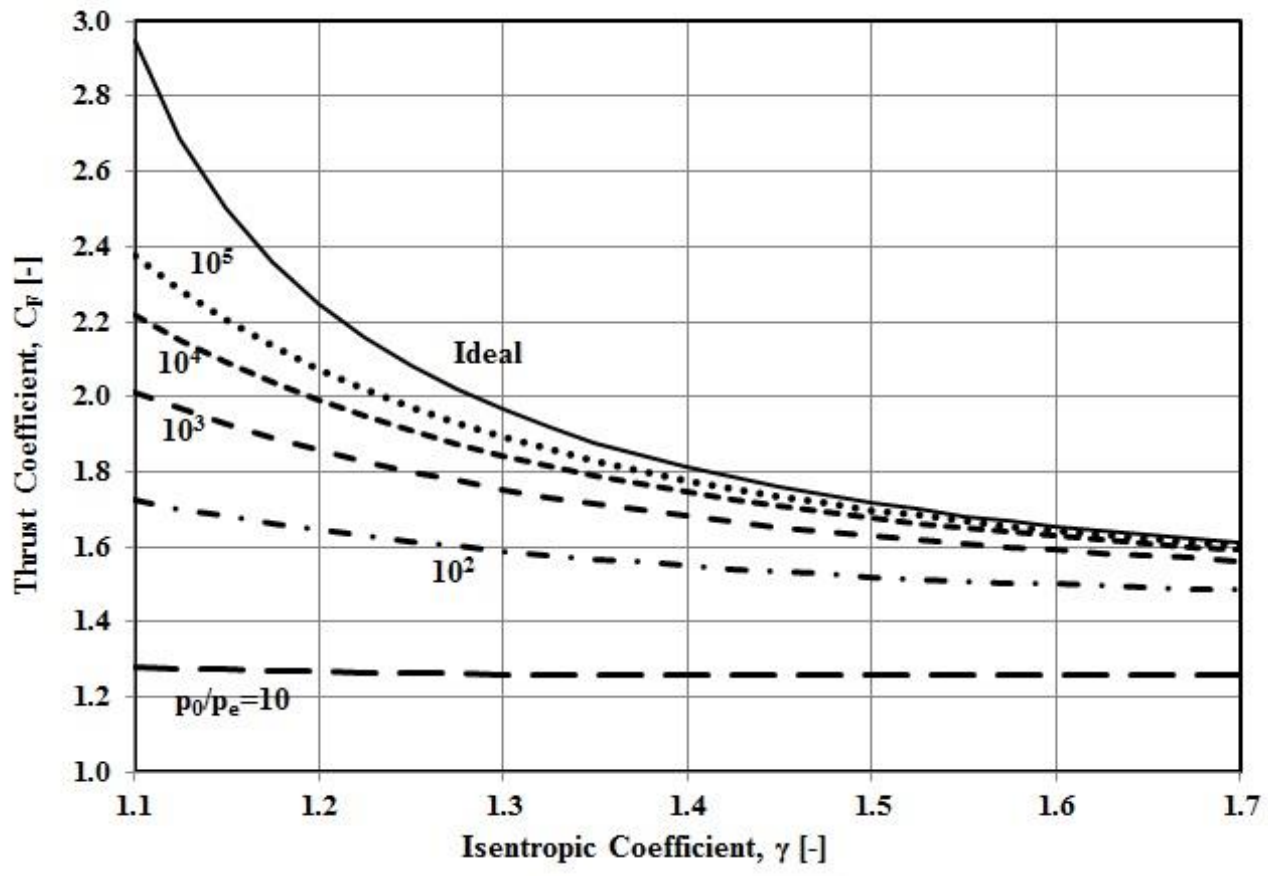

Figure 5. Thrust coefficient $\mathrm{C}_{\mathrm{F}}$ calculations.

Fuel tank are of concentric elliptical cross-section design with LOX tank inclosing LH2 tank (LH2 at $20 \mathrm{~K}$ ) and serving as additional insulator (LOX at 80 $\mathrm{K})$. Cryogenic tanks are only slightly pressurized to prevent turbopump cavitation. A single radial turbine powers both LOX and LH2 turbo-pumps through different gearing ratios. Turbine is powered by gas-generator or staged-combustion cycles 
(Haidn, 2008; Manski et al., 1998). Higher combustion chamber pressures also require more powerful turbo-pumps increasing the weight and power requirements. For example, in order to have combustor pressure of 40 bar (4 $\mathrm{MPa}$ ), turbopumps will need to deliver about 50 bar to account for the losses in the feed system, LOX dome, injector elements, etc. (Daidzic et al., 1991; Humble et al., 1995). For example, an extensive analytical, computational, experimental, and visualization studies of pre-ignition thermal-hydraulic transient processes in MBB's LOX/LH2 HM-7B $3^{\text {rd }}$ stage LRE Ariane IV were investigated in a number of proprietary technical reports by Daidzic (1990a, 1990b, 1991a, 1991b) and also in Daidzic et al. (1991). The flow and thermal problems associated with turbopumps starting and operations, complex transient and steady-state two-phase flows in LOX Domes and injector elements, mixing fuel (LH2) and oxidizer (LOX), combustion and combustion instabilities, thermal processes in combustion chambers and nozzles, etc., are truly extraordinary.

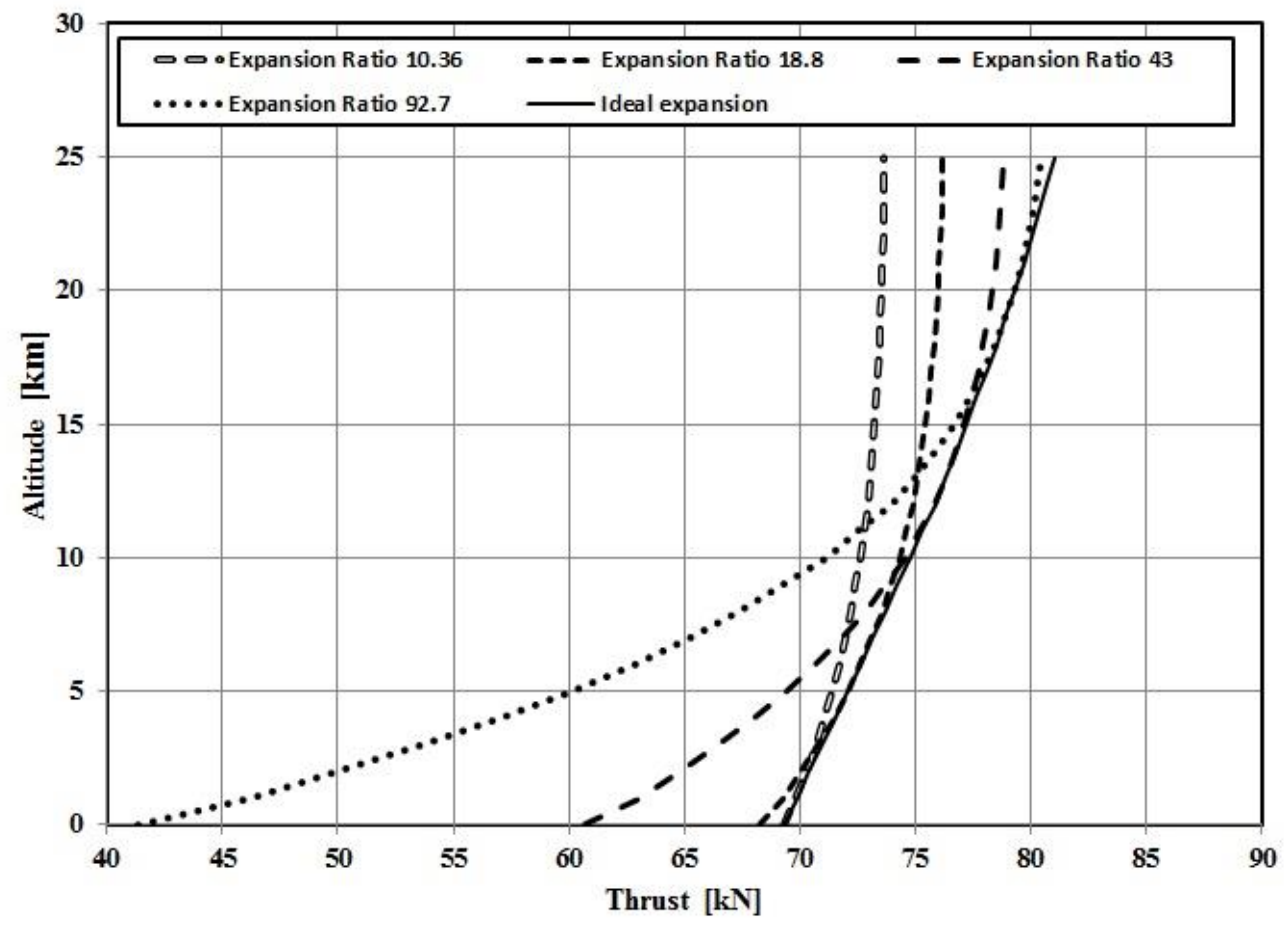

Figure 6. Nozzle expansion ratios as a function of altitude.

The two concentric elliptical-cross-section tanks carry up to $13,100 \mathrm{lb}$ of liquid cryogenic bi-propellants. About $750 \mathrm{lb}$ of LH2 and $350 \mathrm{lb}$ of LOX (rocketassist) are reserved for transatmospheric propulsion. The $\mathrm{O} / \mathrm{F}$ ratio for bi- 
propellant mixture: $O / F=\dot{m}_{L O X} / \dot{m}_{L H 2}$. This ratio is taken to be somewhat fuel-rich at a value of 5 (five) (Haidn, 2008; Humble et al., 1995; Lee, 2014). The amount of $\mathrm{LH} 2$ needed for rocket-mode $(12,000 \mathrm{lb})$ is:

$m_{L H 2}=\frac{m_{P R O P}}{1+O / F}=2,000 \mathrm{lb}=909 \mathrm{~kg}$

The total mass of LH2 is thus $750 \mathrm{lb}$ for transatmospheric ascent for airaugmented rocket-ramjet plus 2,000 $\mathrm{lb}$ for pure rocket-mode vacuum ascent, which is total of $2,750 \mathrm{lb}(1,250 \mathrm{~kg})$. Although, the mass of LOX needed is five times the mass of $\mathrm{LH} 2$, due to the high $\mathrm{LOX} / \mathrm{LH} 2$ density-ratio (LOX at $80 \mathrm{~K} / \mathrm{LH} 2$ at $\left.20 \mathrm{~K}=1,215\left[\mathrm{~kg} / \mathrm{m}^{3}\right] / 71\left[\mathrm{~kg} / \mathrm{m}^{3}\right]=17.1\right)$, more than three times larger $\mathrm{LH} 2$ than the LOX-tanks are needed. This is due to extremely low density of LH2 at about $19-20 \mathrm{~K}$. The amount of LOX for 2,000 lb of LH2 for rocket-only mode is:

$m_{\text {LOX }}=m_{P R O P} \frac{O / F}{1+O / F}=10,000 \mathrm{lb}=4,545 \mathrm{~kg}$

About additional $350 \mathrm{lb}$ of LOX is used for rocket-assist transatmospheric mode requiring total of 10,350 lb LOX. An LH2 tank of about $17.6 \mathrm{~m}^{3}$ and LOX tank of about $3.87 \mathrm{~m}^{3}$ are required minimum $\left(21.5 \mathrm{~m}^{3}\right.$ total). Additional small space for Ullage, boil-off, and volume for unused trapped propellant must be accounted for (Humble et al., 1995; Sutton and Biblarz, 2001). Clearly, the lifting-body spaceplane will have to be long, narrow, and have the RBCC engine integrated with the airframe. We stayed away from utilizing the scramjet concept due to extreme difficulties with the supersonic combustion.

The MMH/NTO hypergolic bi-propellant used for OMS with an O/F ratio of 1.45:1 is used for orbit injection/insertion, orbit circularization, small orbital maneuvers (docking, intercept, rendezvous), and de-orbit. The OMS/RCS fuel tanks are part of the dry structural mass, while the OMS engine, plumbing, etc., weigh about $60 \mathrm{lb}$ with $350 \mathrm{lb}$ in MMH/NTO. The RCS uses 16 pressurized $\mathrm{N}_{2}$ $\left(300+\right.$ bar) cold-gas thrusters $\left(I_{S P}=80 \mathrm{~s}\right)$ weighing about $90 \mathrm{lb}(41 \mathrm{~kg})$ total.

\section{Mission Design}

\section{Launch sites and catapult dynamics}

The additive $\Delta v_{\text {total }}$ can be written for serial multistage launch vehicles (each consisting of different mass-ratios and $\mathrm{O} / \mathrm{F}$ combinations with different 
specific impulses), approximately as the following (Ball and Osborne, 1967; Hill and Peterson, 1992):

$$
\Delta v_{\text {total }}=\sum_{j=1}^{n} \Delta v_{j}=\sum_{j=1}^{n} C_{j} \ln \left(m r_{j}\right) \quad m r_{j}=\left(m_{i} / m_{f}\right)_{j}>1
$$

Another practical (often the only possible) way to deal with the problem of launch vehicles is to introduce staging (in series and/or parallel). Why not get rid of the structure (inert) mass which is no longer needed? The first stage in traditional launch vehicles, such as in the venerable Saturn launch vehicles for Apollo missions (Brooks et al., 2009) is quite inefficient as it has to lift its own weight.

And indeed, we can get rid of the first-stage by utilizing catapult-rail sledassist launch. The idea to use catapult/sled is not new. It has been discussed and proposed many times and especially in the Soviet/Russian designs. Olds and Bellini (1998) have suggested using Maglifter for their highly-reusable Argus SSTO RBCC concept. Catapult launch can be seen as a substitute for an airlaunch. Air-launch automatically implies TSTO design. However, there is no evidence that a practical horizontal catapult-launch spaceplane facility exists. Large savings in structural weights can be achieved by utilizing the nearly horizontal catapult launch system. Several high-elevation equatorial locations have been chosen for the future spaceports (Daidzic, 2011, 2016):

- Kenya (Mount Kenya, 5,199 m at S0 09' 03", E37 $\left.18^{\circ} 27^{\prime \prime}\right)$.

- Tanzania (Kilimanjaro, 5,895 m at S03 $04^{\prime} 33^{\prime \prime}, \mathrm{E} 37^{\circ} 21^{\prime} 12^{\prime \prime}$ )

- Indonesia (Sumatra, Pegunungan Barisan Kerinci peak 3,800 m at S1.697 E101.264 $4^{\circ}$.

- Indonesian part of Papua - West Papua Irian Jaya (Maoke mountains with highest peak Puncak Jaya, formerly known as Carstensz Pyramid at 4,884 $\mathrm{m}$ and located at $\mathrm{S} 04^{\circ} 04.733^{\prime}, \mathrm{E} 137^{\circ} 09.572^{\prime}$ )

- Ecuador (close to Quito, 5,800-6,200 m Andean peaks, close to Equator and around $\mathrm{W} 79^{\circ}$ longitude)

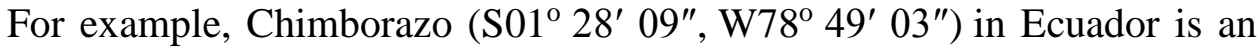
inactive stratovolcano. Its vicinity offers opportunities for building a spaceport. With the peak elevation of 6,268 $\mathrm{m}(20,564 \mathrm{ft})$, Chimborazo is the highest mountain in Ecuador (see Figure 7). It is also the highest peak near the Equator. Its location on the equatorial bulge (Earth is approximately an oblate spheroid) makes its summit the farthest point from the Earth's center on Earth's surface. 
Apart from possible gravitational anomalies, this should be also the place of the lowest local gravitational acceleration on the planet Earth.

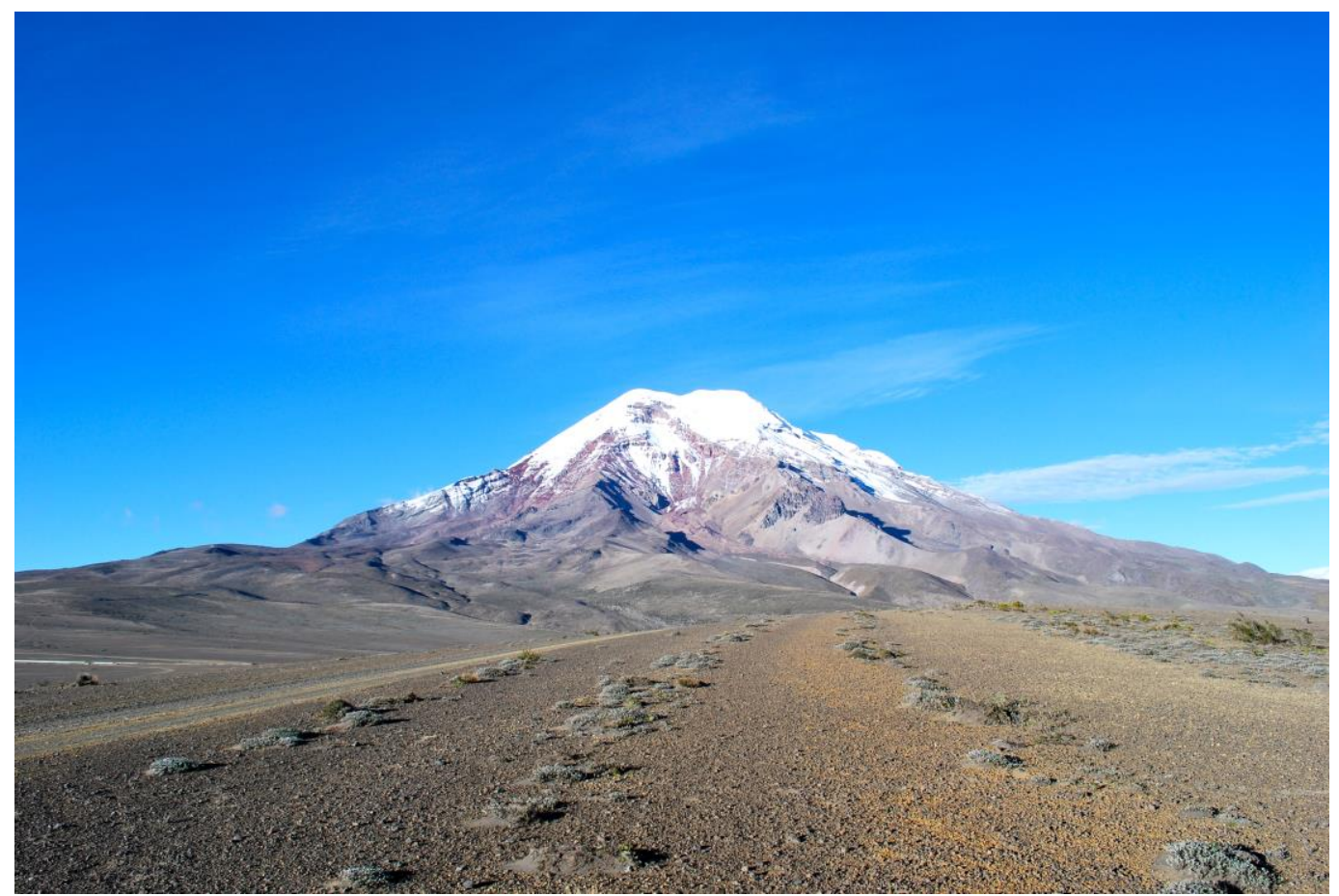

Figure 7. Summit Chimborazo is the highest peak in Ecuador and the highest peak close to Equator (photo credit - https://en.wikipedia.org/wiki/Chimborazo).

There are active volcanoes around some of the aforementioned summits and mountains which would exclude it as an option for building spaceports. Each proposed location is situated close to oceans and large urban areas and commercial airports (Quito, Nairobi, Mombasa, Dar es Salaam, Jakarta, etc.) and provides easterly inertial orbital speed boost for direct equatorial orbits. In emergency, a 4,500-lb, returning-from-space, spaceplane could land at almost any larger commercial runway. Additionally, the local weather conditions are mostly favorable in equatorial regions. A proper site in the vicinity of above mentioned peaks that would accommodate about 10,000 ft long catapult (can be built on the downslope for gravity-assist) and nearby equally long, 200-ft wide, paved runway could possibly be found. A Microwave Landing System (MLS), in addition to onboard redundant IRS and GPS/GNSS Ground-Based Augmentation Systems (GBAS), would be installed for very accurate azimuthal and vertical approach and landing guidance. 
Each possible geographic spaceport location must be carefully surveyed to introduce as little disruption and endanger nearby wildlife and eco-system as possible. Each spaceport must be thoroughly fenced and guarded to prevent intrusion of wildlife and trespassing individuals which could pose significant safety hazard for the operations. Especially, actual catapult launches must be guarded to prevent land animals and birds to disrupt and jeopardize high-speed launches with possible catastrophic consequences. On average it can be ultimately expected to have one launch (and landing) every day in a year in each of the three-five proposed spaceport locations. LH2 (and possibly LOX) would be produced locally as it is difficult, hazardous, and expensive to transport LH2.

Gravity-assist catapult can be regarded as a zero-stage providing about $300-310 \mathrm{~m} / \mathrm{s}(0.3-0.31 \mathrm{~km} / \mathrm{s})$ launch speed. MAGLEV solution could be used to accelerate sled on which spaceplane would be attached (see Figure 8). Local "g" in equatorial regions is about $9.775 \mathrm{~m} / \mathrm{s}^{2}$. Density at $16,000 \mathrm{ft}(4,900 \mathrm{~m})$ is only $60 \%$ of SL air density (Daidzic, 2015a, 2015b) implying less aerodynamic drag, in addition to lower gravitational and steering losses.

If we assume constant average net acceleration (e.g., $20 \mathrm{~m} / \mathrm{s}^{2}$ or about $2 \mathrm{~g}$ ), the catapult speed becomes linear function of time: $v=v_{0}+\bar{a} \cdot t$. Time to launch speed under constant acceleration is then obtained easily. The distance covered from standstill under constant net acceleration is:

$$
s=\int_{0}^{t} v \cdot d t=\bar{a} \int_{0}^{t} t \cdot d t=\bar{a} \cdot \frac{t^{2}}{2} \quad \text { or } \quad s=\cdot \frac{v^{2}}{2 \bar{a}}
$$

The energy that must be used to accelerate the aircraft to catapult release-speed is:

$$
E=\int_{0}^{v} M \cdot v \cdot d v=\frac{m \cdot v^{2}}{2}=\frac{m \cdot \bar{a}^{2} \cdot t^{2}}{2}
$$

The instantaneous power is (Humble et al., 1995):

$$
P=\frac{d E}{d t}=m \cdot \bar{a}^{2} \cdot t=m \cdot \bar{a} \cdot v=\bar{F} \cdot v
$$

For example, the length of the catapult to achieve the launch velocity of $300 \mathrm{~m} / \mathrm{s}$ with constant $30 \mathrm{~m} / \mathrm{s}^{2}$ (about $3 \mathrm{~g}$ ) acceleration, is about $1,500 \mathrm{~m}$ or 4,920 $\mathrm{ft}$. The time required to accelerate to $300 \mathrm{~m} / \mathrm{s}$ at constant $3 \mathrm{~g}$ acceleration is only 
10 seconds. A summary of basic catapult calculations for $2 \mathrm{~g}$ and $4 \mathrm{~g}$ accelerations for various launch speeds $(200-600 \mathrm{~m} / \mathrm{s})$ and no gravity-assist are summarized in Table 4. Installed or design power available (130\% of required) accounts for various losses. In this simple energy analysis, the friction and the potential energy needed to increase height and achieve 5-30 degrees in pitch departure was neglected. A practical catapult-sled system can be designed to launch up to 30,000 lb spaceplanes with desired accelerations from 1.5 (manned) to $4.0 \mathrm{~g}$ (unmanned).

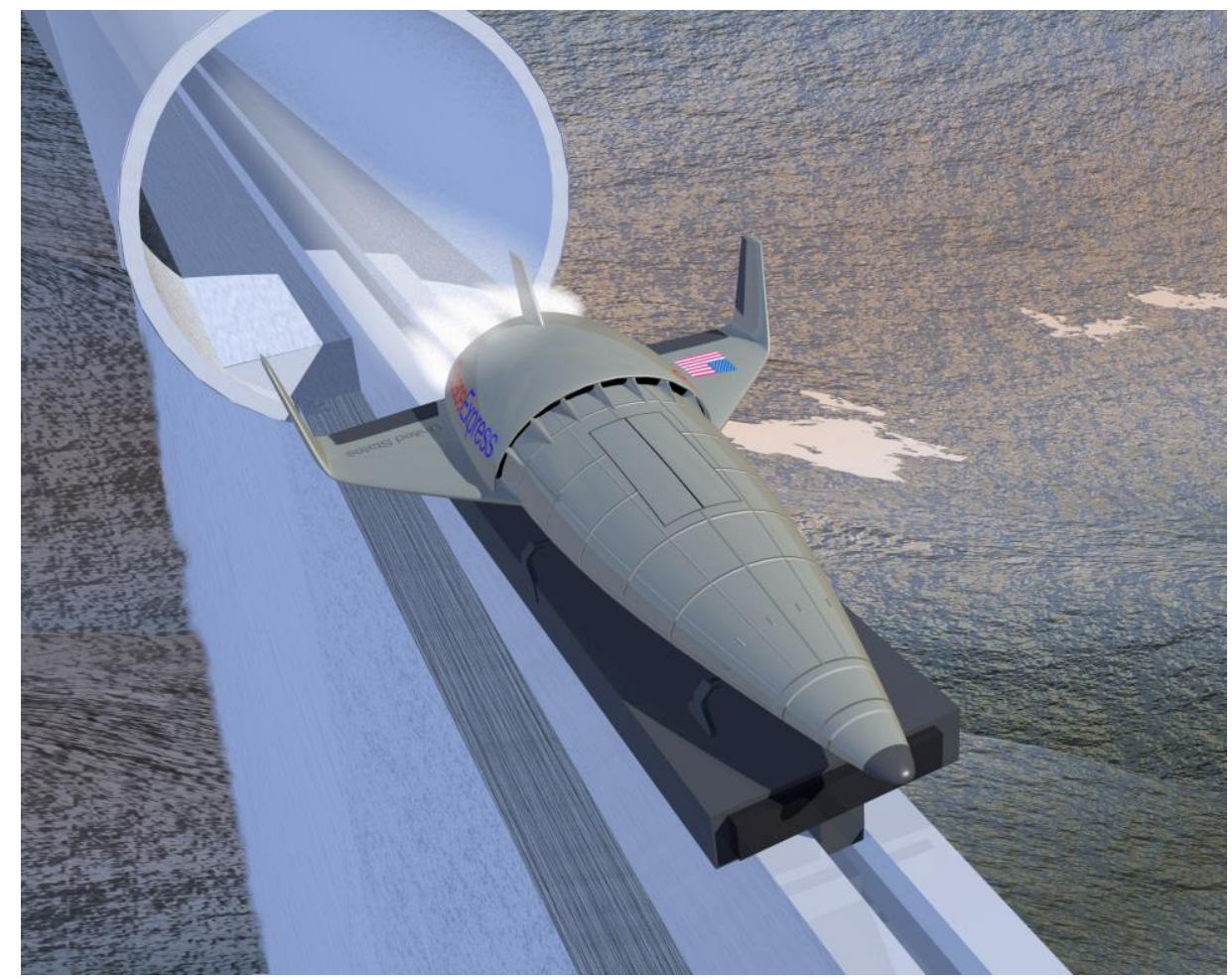

Figure 8. An artist's concept of a fictional RBCC-equipped SSTO utilizing MAGLEV catapult-rail system. Image courtesy of NASA/Marshall Space Flight center (NASA-MSFC).

The catapult peak power must be able to meet all these needs with some additional design margins. Additional, high-g sled breaking distance must be accounted for. A practical catapult system need not exceed length of $10,000 \mathrm{ft}$ $(3,000 \mathrm{~m})$ for nearly-horizontal spaceplane subsonic- to supersonic-Mach launches. There are many advantages, but also some disadvantages in having ground catapult launch as opposed to air-launch from another and much larger airplane. High launch speeds of about $500 \mathrm{~m} / \mathrm{s}$, or more, would enable direct LH2 ramjet propulsion mode with no need for rocket-assist. Another benefit may be 
received from building a catapult on the slope with gravity assisting launches which would optimally utilize hilly terrain in the vicinity of high peaks.

Table 4

Catapult performance characteristics for GLOW 10,909 kg spaceplane

\begin{tabular}{lccccc}
\hline & \multicolumn{5}{c}{ Launch speed [m/s] } \\
\cline { 2 - 6 } & $\mathbf{2 0 0}$ & $\mathbf{3 0 0}$ & $\mathbf{4 0 0}$ & $\mathbf{5 0 0}$ & $\mathbf{6 0 0}$ \\
\hline \multicolumn{1}{c}{$2.0 g$} & 10.20 & 15.30 & 20.39 & 25.49 & 30.59 \\
$\mathrm{t}[\mathrm{s}]$ & $1,019.7$ & $2,294.4$ & $4,078.9$ & $6,373.2$ & $9,177.4$ \\
$\mathrm{~s}[\mathrm{~m}]$ & 214.0 & 214.0 & 214.0 & 214.0 & 214.0 \\
$\mathrm{~F}[\mathrm{kN}]$ & 218.18 & 490.91 & 872.73 & $1,363.64$ & $1,963.64$ \\
$\mathrm{E}[\mathrm{MJ}]$ & 42.79 & 64.19 & 85.59 & 106.98 & 128.38 \\
$\mathrm{P}_{\text {req }}[\mathrm{MW}]$ & 55.63 & 83.45 & 111.26 & 139.08 & 166.89 \\
$\mathrm{P}_{\text {dsgn }}[\mathrm{MW}]$ & & & & & \\
$\quad 4.0 g$ & 5.10 & 7.65 & 10.20 & 12.75 & 15.30 \\
$\mathrm{t}[\mathrm{s}]$ & 509.9 & $1,147.2$ & $2,039.4$ & $3,186.6$ & $4,588.7$ \\
$\mathrm{~s}[\mathrm{~m}]$ & 427.9 & 427.9 & 427.9 & 427.9 & 427.9 \\
$\mathrm{~F}[\mathrm{kN}]$ & 218.18 & 490.91 & 872.73 & $1,363.64$ & $1,963.64$ \\
$\mathrm{E}[\mathrm{MJ}]$ & 85.59 & 128.38 & 171.17 & 213.96 & 256.76 \\
$\mathrm{P}_{\text {req }}[\mathrm{MW}]$ & 111.26 & 166.89 & 222.52 & 278.15 & 333.78 \\
$\mathrm{P}_{\text {dsgn }}[\mathrm{MW}]$ & \multicolumn{5}{c}{} \\
\hline
\end{tabular}

\section{Ascent and orbit injection dynamics}

After safely clearing the catapult, the RBCC engine will deliver $100 \%$ thrust and the spaceplane will roll to establish a correct launch azimuth angle (if required) and commence moderate-gradient accelerating climb using combined air-rocket thrust, as needed, so as to achieve $M \approx 3(900 \mathrm{~m} / \mathrm{s})$ at $18 \mathrm{~km}$ elevation $(59,000 \mathrm{ft})$ at about 65-70 degrees pitch angle. The RBCC's LRE is supporting afterburning ramjet mode until about Mach 1.8, after which full 15,000 lbf ramjet thrust is available. The initial acceleration-climb trajectory would be optimized for the spaceplane to stay below the max-Q limit. As the spaceplane starts pitching up to assume a steep accelerating climb, the two, each 3,000 lb heavy, HRBs with $\mathrm{T} / \mathrm{W}=3.67: 1$ are ignited providing thrust-kick of 22,000 lbf. Unlike Solid Rocket Boosters (SRB), HRBs can be throttled and even shut down if needed for mission abort. This is now a total of 37,000 lbf with the initial T/W of about 1.61. As needed, the airbreathing thrust-mode is supplemented by an RBCC's rocket-mode while accelerating the spaceplane in a GT-maneuver so as 
to achieve about $M \approx 7(2,300 \mathrm{~m} / \mathrm{s})$ at the altitude (in reference to mean spherical Earth) of $110 \mathrm{~km}(360,000 \mathrm{ft})$ and about 115 seconds after HRBs ignition.

The acceleration from $900 \mathrm{~m} / \mathrm{s}(M \approx 3)$ to $2,300 \mathrm{~m} / \mathrm{s}(M \approx 7)$ is to occur over about 100 seconds delivering tolerable average acceleration of about $1.43 \mathrm{~g}$. Predominantly $15,000 \mathrm{lbf}(53.5 \mathrm{kN})$ ramjet mode with subsonic combustion will be used for this boosted accelerating vertical climb through atmosphere to take advantage of atmospheric oxygen. At a height of 110-120 km and about $200 \mathrm{~km}$ downrange, the two HRBs (with combined dry weight of $500 \mathrm{lb}$ ) are jettisoned, parachuted, recovered, and reused (like SRBs/SRMs in retired STS Space Shuttle).

The RBCC engine is now fully re-configured for a rocket-only mode providing up to $25,000 \mathrm{lbf}$ of thrust (can be throttled from $50 \%$ to $100 \%$ ) to take now about $17,000 \mathrm{lb}$ spaceplane $(\mathrm{T} / \mathrm{W}=1.47)$ to $300-\mathrm{km}$ LEO. Maximum ascent T/W ratio is 1.85 and the LRE is throttled back as needed to maintain given longitudinal acceleration. The illustration of the flight trajectory and critical mission altitudes is depicted in Figure 9. Spaceplane stability and control is not discussed here. For practical purposes it is assumed that at $110+\mathrm{km}$, the ascent is in practical vacuum with no aerodynamic drag. With HRBs separated, the spaceplane is now accelerated from $2,350 \mathrm{~m} / \mathrm{s}$ to $7,265 \mathrm{~m} / \mathrm{s}$ in reference to topocentric (spaceport) frame-of-reference. For a 300-km circular LEO that would be $7.72989 \mathrm{~km} / \mathrm{s}$ in reference to inertial geocentric frame-of-reference. The amount of propellant needed for achieving given $\Delta v$ with given propulsion system can be estimated from (Humble et al., 1995):

$m_{\text {prop }}=m_{i}-m_{f}=m_{i}\left[1-\exp \left(-\frac{\Delta v}{I_{S P} g_{0}}\right)\right]=m_{f}\left[\exp \left(\frac{\Delta v}{I_{S P} g_{0}}\right)-1\right]$

For the average ideal specific impulse of $455 \mathrm{~s}$, the required $\Delta v$ of about $4,965 \mathrm{~m} / \mathrm{s}$, the initial spaceplane mass of 17,000 lbf (at about $120 \mathrm{~km}$ after HRBs separation), the ideal bi-propellant weight becomes 11,350 lbf. Additional $650 \mathrm{lbf}$ of LH2/LOX bi-propellant accounts for remaining gravitational and other losses. At $120-130 \mathrm{~km}$, the spaceplane is almost half way to LEO and has about one-third in orbital kinetic energy requirements. The sustainer LRE bi-propellant amounts are really very tight with no room for error. At orbital insertion, the originally $24,000 \mathrm{lb}$ heavy spaceplane weighs only about 4,500 lb $(2,045 \mathrm{~kg})$ of which 660 lb (300 kg) could be payload (including human crew). The terrestrial prograde (direct) inertial orbital boost of about $465 \mathrm{~m} / \mathrm{s}$ is added to the burnout (final) speed for easterly launch azimuth (zero inclination orbit) from equator to yield the 
needed 300-km LEO orbital speed in geocentric frame-of-reference. The catapult launch speed of about $300 \mathrm{~m} / \mathrm{s}$ and the terrestrial equatorial inertial speed almost cancel out losses due to gravity, aerodynamic drag, steering, etc. The mission design delta-v is expressed as:

$$
\Delta v_{\text {design }}=v_{\text {LEO }}+\Delta v_{\text {gravity }}+\Delta v_{\text {Drag }}+\Delta v_{\text {steering }} \mp \Delta v_{\text {rotation }}
$$

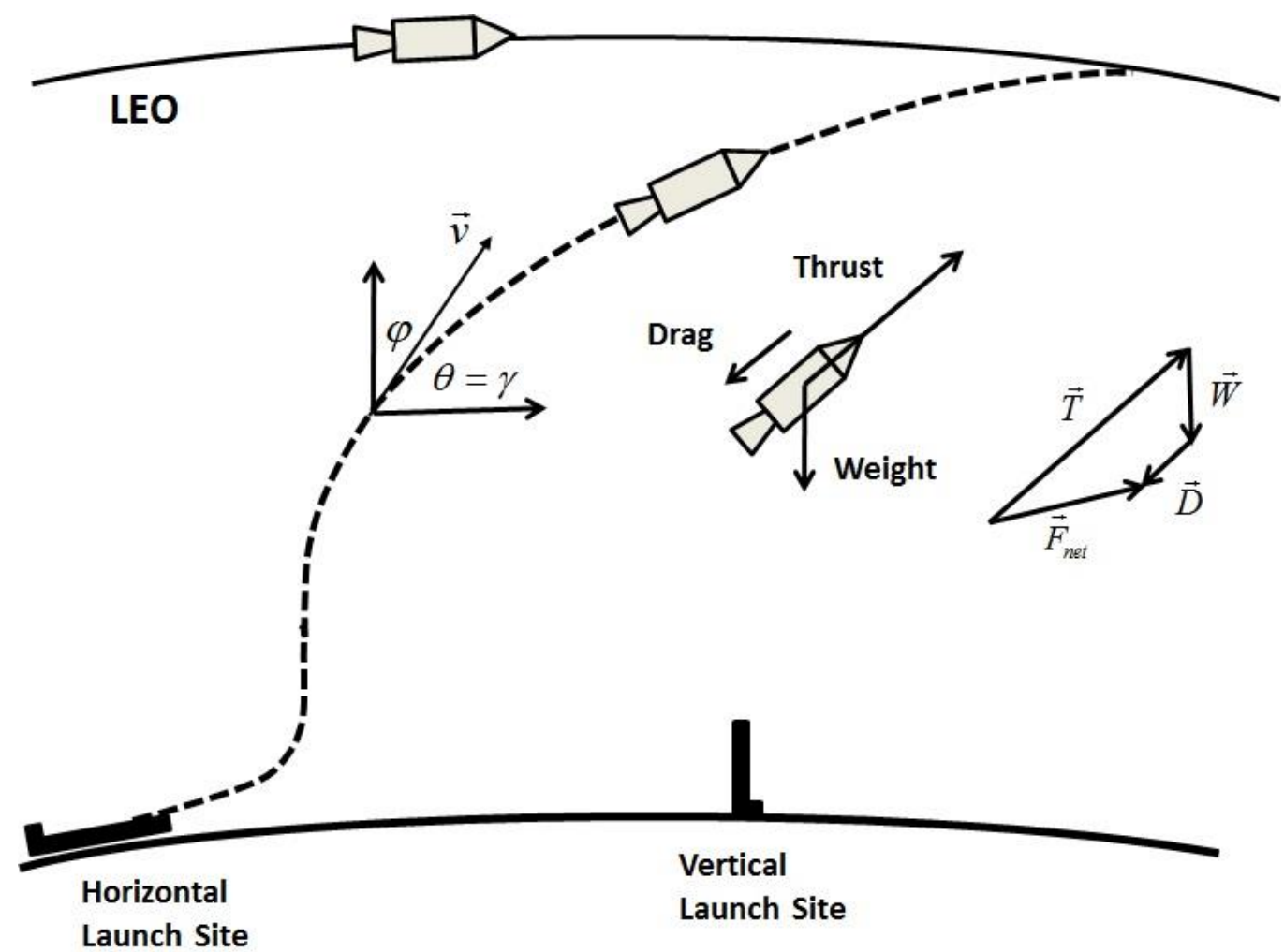

Figure 9. Spaceplane GT $(\gamma=\theta, \alpha=0)$ trajectory when launched nearly horizontally. Not to scale.

Onboard Orbital Maneuvering System (OMS), utilizing $\mathrm{N}_{2} \mathrm{O}_{4} / \mathrm{MMH}$ with effective $\mathrm{I}_{\mathrm{SP}}$ of $315 \mathrm{~s}$, is used for final orbit injection and circularization.

If another orbital inclination angle is sought (apart from equatorial), the launch azimuth is approximately, $\sin \beta=\cos i / \cos \psi$. For the launch from the Equator where latitude angle, $\psi=0$, a simple relationship follows, $\sin \beta=\cos i$. For example, an orbital inclination, $i=30^{\circ}$, a launch azimuth (measured from the 
true North) required will be $\beta=60^{\circ}$. A huge benefit of equatorial launches is that launch windows will always exist (Bate et al., 1971; Sellers, 2005) and considering ultimately three facilities at different longitudes, these launch windows will open frequently every day. While not full benefit of easterly terrestrial rotation can be then taken, it is still far better than trying to change orbit inclinations while in LEO. The easterly inertial speed comes from Earth's rotation $v_{e}=\left(R_{e} \omega_{E}\right) \cdot \cos \psi \approx 465.1 \times \cos \psi$, where the sidereal day is $23 \mathrm{~h} 56 \mathrm{~min}$ and 4.0905 seconds (about 86,164.1 s) and equatorial radius is $6,378.137 \mathrm{~km}$. The IERS/ITRS and WGS-84 standards use average $\omega_{E}=7.292115 \times 10^{-5} \mathrm{rad} / \mathrm{s}$.

Derivation and analytical solution of GT ascent trajectory in the case of constant (T/W) ratio, negligible aerodynamic drag, and constant terrestrial gravitational acceleration is presented in Appendix B. Calculations of zero-drag GT trajectory were performed using the constant T/W value of 1.90 and are shown in Figure 10. The spaceplane peaked at 406-km height at suborbital 6,750 $\mathrm{m} / \mathrm{s}$ and 482 seconds (about 8 minutes) after initiating GT. As it starts slow descend it picks up speed. Subsequent orbital maneuver can bring it to desired circular LEO. The GT started with the initial engine gimbaling (steering) maneuver pitch change of 4 degrees from the vertical at a speed of $165 \mathrm{~m} / \mathrm{s}(320$ KTAS) and a height of $1,000 \mathrm{~m}$. While it is possible to maintain constant T/W ratio for most of the ascent (throttling LRE), this simple theory cannot account for aerodynamic drag losses and variable gravity, but still produces useful results.

\section{Ascent trajectory modeling and simulation}

The mathematical model of rigid rocket motion for spherical rotating Earth with several coupled nonlinear ODEs can be found in Ashley (1992), Vinh (1993), Tewari (2007), and Weiland (2010). The geocentric reference frame would be fixed (to distant stars), sufficiently inertial, frame of reference. Often it is possible to use non-rotating spherical Earth or even non-rotating flat-Earth approximations for faster and simpler computations. We thus neglected Coriolis and centrifugal accelerations using simple topocentric non-rotating flat-Earth slightly non-inertial frame (Ball and Osborne, 1967; Etkin, 1959, 2000; Kolk, 1961; Tewari, 2007; Thomson, 1986; Vinh, 1993; Weiland, 2010). Only rocket propulsion exists in a very rarefied atmosphere. Assuming zero-AOA GT trajectory, the set of ODE describing dynamic and kinematic relationships is: 


$$
\begin{aligned}
& m \frac{d v}{d t}=T(h)-D(h)-m \cdot g(h) \sin \theta \\
& m v \frac{d \theta}{d t}=\left\{\begin{array}{cc}
0 & h_{0} \leq h \leq h_{G T} \\
-m \cdot g(h) \cos \theta & h_{G T}<h \leq h_{L E O}
\end{array}\right\} \\
& \frac{d m}{d t}=-\dot{m}_{p r o p} \\
& \frac{d h}{d t}=v \sin \theta \\
& \frac{d x}{d t}=v \cos \theta
\end{aligned}
$$

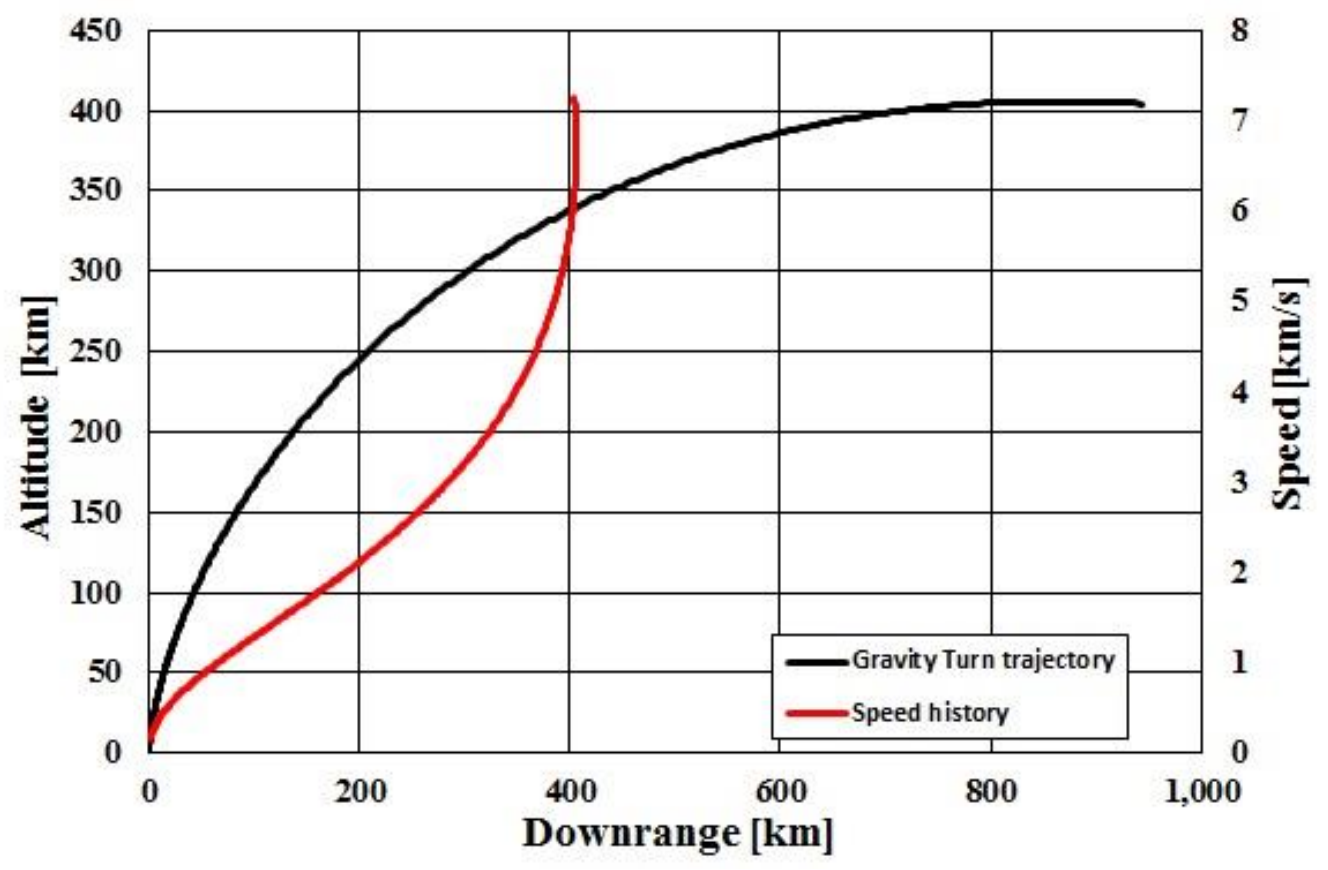

Figure 10. Result of analytical GT trajectory computation.

The initial conditions (ICs) for integration are:

ICs: $\quad v^{0}=v_{0} \quad \theta^{0}=\theta_{0} \quad m^{0}=m_{0} \quad h^{0}=h_{0} \quad x^{0}=x_{0}$

The same set of equations was used for GT transatmospheric ascent, with different engine and booster models and accounting for aerodynamic drag. The aerodynamic drag and the ballistic coefficient (BC) are given as: 


$$
\begin{aligned}
& D=\frac{\rho(h)}{2} v^{2} C_{D}(M) A_{r e f}=\frac{m \cdot \rho(h)}{2 \cdot B C} v^{2} \quad B C=\frac{m}{C_{D} A_{r e f}}=\frac{m}{A_{e f f}} \\
& a_{S L}=340.29 \mathrm{~m} / \mathrm{s} \quad\left(C_{D} A_{r e f}=A_{e f f}=\mathrm{const}\right) \quad C_{D}=0.2 \quad A_{r e f}=3.5 \mathrm{~m}^{2}
\end{aligned}
$$

Thrust of RBCC engine is a function of propulsion mode and altitude. To keep acceleration constant, thrust is reduced as the vehicle becomes lighter. Since the effective exhaust speed is constant, that implies propellant mass flow rate is reduced at the same proportion. The ascent acceleration used was between $1.5 \mathrm{~g}$ to $2.2 \mathrm{~g}$ for manned flights. The total coefficient of drag $\mathrm{C}_{\mathrm{D}}$ is a complex function of Mach and Reynolds numbers, sideslip angle, and the coefficient of lift $\mathrm{C}_{\mathrm{L}}$. It will experience dramatic changes going through subsonic, transonic, supersonic, and hypersonic regimes (Ashley, 1992; Vinh, 1993):

$C_{D}(M)=C_{D, 0}(M)+K(M) \cdot C_{L}^{2}$

Parasitic, vortex, and wave drag must be all accounted for. Fortunately, during atmospheric ascent the spaceplane clears dense atmosphere before it accelerates to high Mach numbers. Hypersonic drag and intense aerothermal effects become a real problem during atmospheric re-entry. It is assumed that sideslip is maintained zero at all times by the flight control and guidance systems. For most of the climb, the lift coefficient is zero due to GT. By neglecting the Reynolds-number dependence and the transient flight through transonic region, we assume the constant value of $\mathrm{C}_{\mathrm{D}}$ for this spaceplane design of 0.20 (Sutton and Biblarz, 2001; Tewari, 2007) at high Mach numbers (M > 3). Of course, in a very detailed and complex flight trajectory calculations, drag changes with Mach number, atmospheric wind changes with altitude, and other factors would have to be included. Constitutive relationships for gravitational acceleration and air density as functions of orthometric (MSL) reference Geoid altitude are:

$$
\begin{aligned}
& g(h)=g\left(\phi_{G D}\right) \cdot\left(\frac{R_{0}}{R_{0}+h}\right)^{2} \quad \rho_{\text {AIR }}(h)=\rho_{0} \cdot \exp \left[-\frac{g(h) \cdot h}{R_{A I R} \cdot T_{0}}\right] \\
& R_{0}=6,371 \mathrm{~km} \quad \rho_{0}=1.752 \mathrm{~kg} \mathrm{~m}^{-3} \quad R_{A I R}=287.053 \mathrm{~J} \mathrm{~kg}^{-1} \mathrm{~K}^{-1} \quad T_{0}=229 \mathrm{~K}
\end{aligned}
$$

The isothermal atmospheric model used here is valid above $5 \mathrm{~km}$ elevation and approximately up to $120 \mathrm{~km}$ (Ashley, 1992; Chapman, 1958; Daidzic, 2015a, 2015b; Hill and Peterson, 1992; Tewari, 2007). According to Stacey and Davis (2008), the International Gravity Formula represents the current model of Earth's 
gravitation which includes the rotation of the Earth and in geodetic latitude is expressed as:

$$
g\left(\phi_{G D}\right)=9.780327 \cdot\left[1+0.0053024 \cdot \sin ^{2}\left(\phi_{G D}\right)+0.0000059 \cdot \sin ^{2}\left(2 \phi_{G D}\right)\right]
$$

This is the reference variation of gravity and any deviation from it is referred to as gravitational anomaly. The circular inertial orbital speed is:

$v_{L E O}=\sqrt{\frac{G M_{E}}{R_{0}+h_{L E O}}} \approx 2 \times 10^{7}\left(R_{0}+h_{L E O}\right)^{-1 / 2}[\mathrm{~m} / \mathrm{s}]$

where,

$G M_{E}=\mu_{E}=3.986004418 \times 10^{14} \mathrm{~m}^{3} / \mathrm{s}^{2} \quad R_{0}=6.371 \times 10^{6} \mathrm{~m}$

The Earth's polar radius is $6,356.8 \mathrm{~km}$ and the equatorial radius is $6,378.137 \mathrm{~km}$. The spherical-average radius is $6,371 \mathrm{~km}$. The set of ODE (Equation 17) and the algebraic constitutive relationships (Equations 18-22) can be integrated numerically using advanced, variable-step, active convergence with error control ODE solvers (Carnahan et al., 1969; Chapra and Canale, 2006; Press et al., 1992). And indeed we have done so using various sophisticated variablestep, in-house developed and built-in, ODE solvers in Matlab R2015, True Basic v6.0, and Fortran 90/95/2003/2008 with IMSL numerical libraries. However, a simple numerical solver, with minimum programming effort required and based on the Euler forward-time fixed single-step integration (Carnahan et al., 1969; Chapra and Canale, 2006; Press et al., 1992) for vacuum rocket-only mode is presented in Appendix C. This solver is reasonably accurate for shorter flight durations. The same solver was used for transatmospheric ascent where aerodynamic drag is a significant force. The transatmospheric and vacuum (above $110 \mathrm{~km}$ ) ascents were approximately stitched together. The RBCC engine modes are very different for transatmospheric and rocket-only propulsion mode and the desire was not to complicate the simulation model too much for this conceptual study.

\section{Orbital maneuvers and atmospheric re-entry}

The return to earth from LEO is accomplished by one-burn de-orbit maneuver. It is essentially an interrupted Hohmann transfer ellipse where the perigee of the lower (and closer) orbit can be set at about 30-100 km to control the angle of atmospheric re-entry. Once at about $120-125 \mathrm{~km}(400,000 \mathrm{ft})$, the 
spaceplane, now accelerated above 300-km LEO orbital speed, will start encountering aero-braking from increasingly thicker atmosphere. The re-entry angle must be carefully chosen and controlled to optimize between aero-thermal heating and powerful deceleration forces. Clearly the Keppler's laws of orbitalmechanics are no longer valid. The spaceplane will perform maneuvering gliding re-entry. The de-orbit maneuver is illustrated in Figure 11.

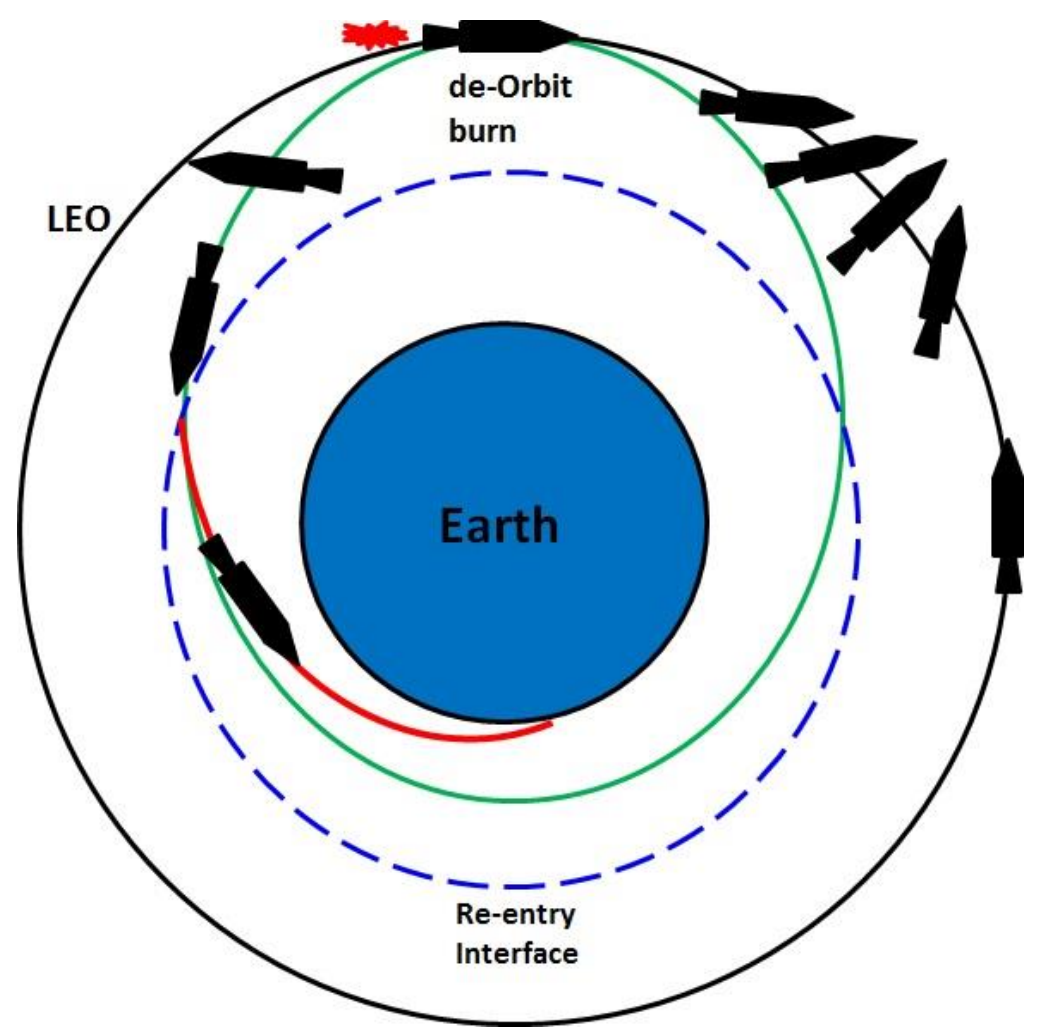

Figure 11. An illustration of de-orbit maneuver. Perigee of the Hohmann's transfer orbit need not be set at Earth's surface. Not to scale.

Typically, the OMS system is used for initiating de-orbit maneuver. We planned using toxic $\mathrm{MMH} / \mathrm{N}_{2} \mathrm{O}_{4}$ hypergolic bi-propellants with the gimbaled high expansion-ratio nozzle space-engine with the effective ISP of 315 s for OMS. This is similar to Space Shuttle Orbiter's OMS (Humble et al., 1995; Sutton and Biblarz, 2001). Spaceplane could use cold-gas RCS thrusters for attitude control (pitch, roll and yaw rotations). However, more energetic, toxic, but with flight heritage, hydrazine $\left(\mathrm{N}_{2} \mathrm{H}_{4}\right)$ mono-propellant ( $\mathrm{I}_{\mathrm{SP}}$ of about $240 \mathrm{~s}$ ), or alternatively low-ISP and with little flight heritage, but environmentally friendly, Hydrogen- 
Peroxide $\mathrm{H}_{2} \mathrm{O}_{2}$, could be used as substitutes. Another substitute for RCS could be before mentioned MMH/UDMH (organic compounds of Hydrazine) in combination with NTO (Humble et al., 1995; Sellers, 2005; Sutton and Biblarz, 2001). The final design would depend on complex optimization and tradeoff between the system simplicity, reliability, weight, performance, and safety.

The speed reduction required for initiating the Hohmann elliptical transfer from 300-km LEO and given deorbit perigee height $\mathrm{H}_{\text {deorbit }}$ can be calculated using the following equation from Thomson (1986) with the $2^{\text {nd }}$ form derived independently by this author:

$$
\Delta v=v_{L E O} \cdot\left[1-\sqrt{\frac{2\left(R_{0}+H_{\text {deorbit }}\right)}{2 R_{0}+h_{L E O}+H_{\text {deorbit }}}}\right] \approx \frac{v_{L E O}}{4}\left[\frac{2\left(h_{L E O}-H_{\text {deorbit }}\right)}{2 R_{0}+H_{\text {deorbit }}+h_{L E O}}\right]
$$

After substituting known values, a retro-burn of about $59 \mathrm{~m} / \mathrm{s}$ (to start accelerating transfer-orbit descent to lower orbit) is required for 100-km transferorbit perigee. About $80.5 \mathrm{lb}$ of Mono-Methyl-Hydrazine (MMH) fuel and Nitrogen TetrOxide (NTO) oxidizer is required to de-orbit from 300-km LEO. For minimum-energy co-planar co-tangential Hohmann orbital transfer from circular 300-km LEO to circular 400-km LEO, where the International Space Station (ISS) is located, will take two OMS firings, the first of $28.7 \mathrm{~m} / \mathrm{s}$, and a second $28.6 \mathrm{~m} / \mathrm{s}$, for a total $\Delta v$ of $57.3 \mathrm{~m} / \mathrm{s}$. The Time-of-Flight (TOF) for transfer is about 46 minutes and it would take $78.1 \mathrm{lb}$ of MMH/NTO. To de-orbit from 400$\mathrm{km}$ LEO with deorbit perigee height of $80 \mathrm{~km}$, the 4,250-lb spaceplane would need $\Delta v$ of about $93 \mathrm{~m} / \mathrm{s}(305 \mathrm{fps})$ with the MMH/NTO amount used of $126.6 \mathrm{lb}$ $(57.5 \mathrm{~kg})$. The orbital inclination changes are prohibitively propellant-expensive. To change orbital inclination by just 1 (one) degree, for the same orbital weight, the spaceplane would need $\Delta v$ of about $135 \mathrm{~m} / \mathrm{s}$ with the $182 \mathrm{lb}$ of hypergolic $\mathrm{MMH} / \mathrm{NTO}$. There is only about $350 \mathrm{lb}(159 \mathrm{~kg})$ of MMH/NTO bi-propellant available onboard the spaceplane. Without orbiting space gas-stations and kickmotors available to be picked-up and used, any orbital inclination change or making larger orbital maneuvers would be prohibitive. All what is left is enough propellant for deorbit, some limited orbital transfers, attitude control (cold gas $\mathrm{N}_{2}$ ) and some basic maneuvering (Huges, 2004) for docking/rendezvous, etc. A skip re-entry could enable spaceplane to commence orbital inclination changes (Weiland, 2010) without much propellant expenditure.

The physics of re-entry is very complicated and is not discussed in this conceptual study. For more details on re-entry physics consult Chapman (1958), Regan and Anandakrishnan (1993), Sellers (2005), Tewari (2007), and/or Vinh 
(1993). For accurate predictions the re-entry model must account for Earth rotation and sphericity (geocentric inertial frame of reference). A separate article is envisioned in the future that will tackle problems of re-entry deceleration, heat transfer, overall heat absorption, and cooling methods. A proposed spaceplane need to be designed to safely endure 350-500 atmospheric re-entries. Required maintenance must be performed after each flight during its life cycle.

\section{Cost analysis}

It is, of course, very hard to give reliable cost predictions for future space systems and missions which also depend on technological developments. The presented cost analysis is rudimentary and no claim to high accuracy is claimed. There are many degrees-of-freedom, most of them unknown, that can affect the final cost. Nevertheless, we found it important to give at least an order-ofmagnitude cost predictions. Most of the technologies and materials required for this catapult-assisted RBCC SSTO parallel-boosted spaceplane concept already exist. Flight testing proposed ramrocket RBCC engine would be required to consistently deliver required performance as suggested here.

It is estimated that the cost of designing, obtaining land lease, and building each equatorial, high-altitude spaceport with catapult facility, 10,000 ft long and 150 - $\mathrm{ft}$ wide fully instrumented asphalt runway, and all associated infrastructure would cost 2 (two) billion in today's US\$. Facilities to produce and/or store some of the propellants (LOX, LH2, $\mathrm{N}_{2}, \mathrm{NTO}, \mathrm{MMH} / \mathrm{UMDH} / \mathrm{N}_{2} \mathrm{H}_{4}$ ) must be accounted for. Electric power distribution with internal emergency power generation is a must. A banks of super-capacitors could be used for rapid catapult electrical power supply. For three spaceports (e.g., Ecuador, Tanzania, and Indonesia) that would be 6 billion US\$ if there were all built at the same time. Each facility would employ personnel of about 120-150 trained technicians, mechanics, engineers, and other profiles and about 40-50 specially trained pilots/astronauts (pilotnauts).

Design, testing and manufacturing each spaceplane with RBCC engine and all systems could cost about 100 million US\$ per unit if 40 are delivered. Each spaceport would operate 10 spaceplanes with 3-4 spare. The life-cycle of each spaceplane would be 10-15 years with required maintenance and about 35 cycles/missions per year per unit. The total investment cost in spaceplanes would then be 4 billion US\$. In order to build and place orbiting space gas-stations, mini space shelters/stations, and orbital kick-motors in designated LEO, an investment of about 3 billion US\$ is required. To launch such items, the existing heavy-lift launchers are required. The total investment for completed and mission-ready 
three facilities, spaceplanes and required space-infrastructure would be thus about 13 billion US\$. For comparison NASA's annual budget in 2015 was about 18 billion US\$. Naturally, only one facility could be built initially and only 5-10 multipurpose spaceplanes built. Such horizontal catapult-assist spaceports make financial sense only for high frequency of launches.

All three space launch facilities with about 1,000 launches per year and associated cost of 900,000 US\$ per launch (propellants, catapult, maintenance, operations, flight crew, personnel, insurance, etc.) would then need about one billion US\$ annually. If the return-on-investment is expected in 8-10 years that implies profit of about 2.5-3 billion US\$ every year from all three facilities. If the average prorated conservative cost (all operating and fixed cost included) of a single mission is $\$ 900,000$ for payload of $300 \mathrm{~kg}$ (including human payload) that would imply launch cost (in today's US\$) of about $\$ 3,000 / \mathrm{kg}$ (realistically could be less). It is a rather common human tendency to frequently underestimate the future cost of a project. Nevertheless, this figure is still an order-of-magnitude lower than, for example, STS Space Shuttle mission which delivered average payload of $20,000 \mathrm{~kg}$ for the cost of almost 1 billion US\$ or about 40,000-50,000 $\mathrm{US} \$ / \mathrm{kg}$.

Consider also that each multipurpose spaceplane may return $100-200 \mathrm{~kg}$ of collected space junk or other items per mission at a cost of about $\$ 2,000 / \mathrm{kg}$. That would be about $\$ 200,000$ to $\$ 400,000$ additional earning per mission or about 150 million US\$ income per year on average. Reducing the amount of space junk and debris in LEO is certainly an important civilizational interest. Such spaceplanes could be used as space-taxi to transport people and materials to and from orbiting space stations (space tourism) and as emergency escape vehicle. A comprehensive analysis of space transportation systems including their design and cost analysis is given in Hammond (1999). The author also briefly discusses future NASA's fully reusable RBCC SSTO vehicles as a means to significantly reduce launch costs and provides figure (an overly optimistic in our view) of $\$ 300-\$ 600$ per pound (in late 1990's US\$).

\section{Results and Discussion}

The results of transatmospheric and vacuum ascent trajectories were solved and presented separately. Only limited numerical trajectory optimizations were performed. The part of accelerating climb up to $18 \mathrm{~km}$ and reaching $900 \mathrm{~m} / \mathrm{s}$ $(2,000$ knots) are not shown. The ascent trajectory and propellant remaining (solid/liquid HRB propellants and ramjet-LH2) mass as a function of downrange 
distance for transatmospheric flight while performing GT climb is shown in Figure 12. Similarly, transatmospheric ascent time-history is shown in Figure 13.

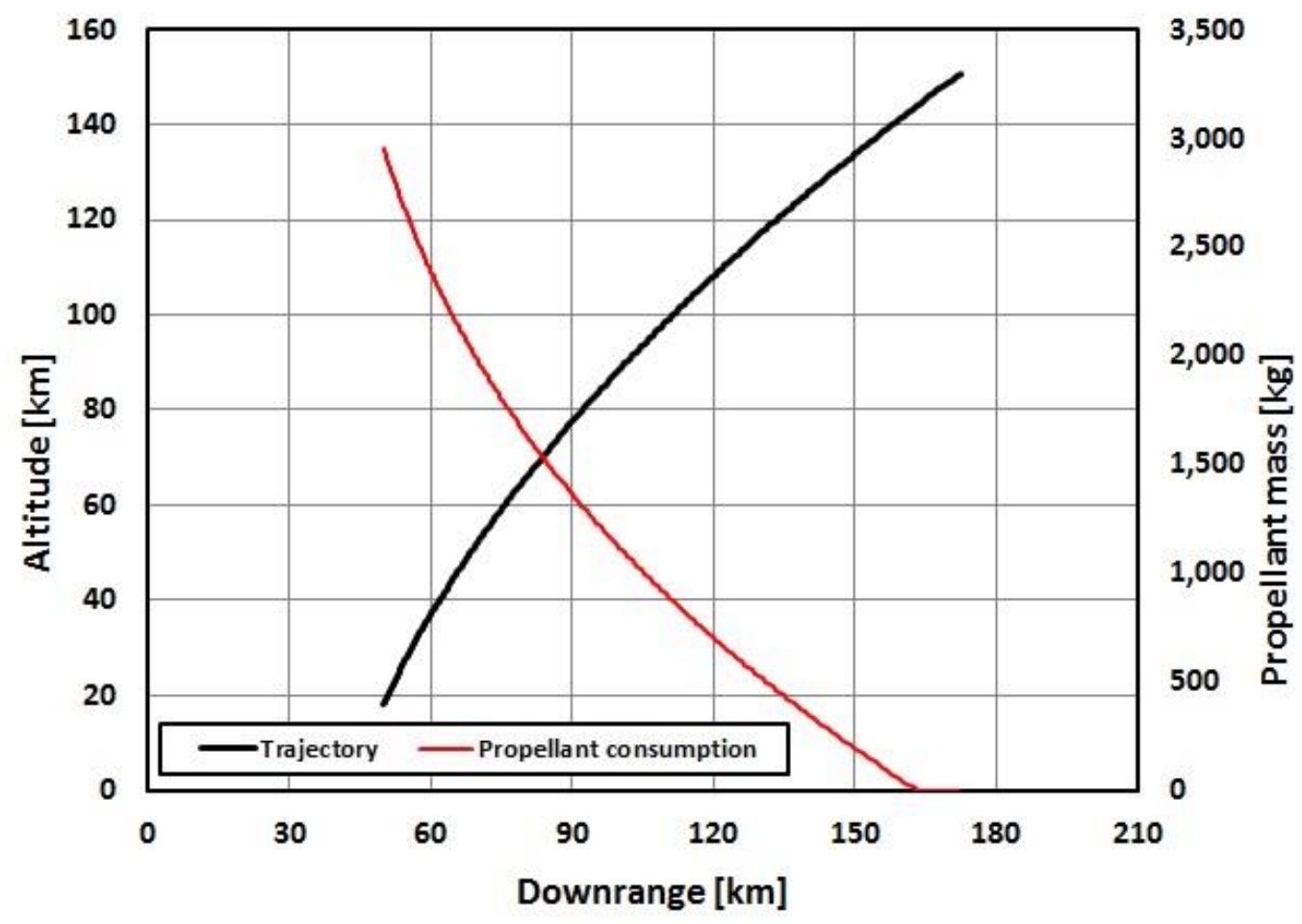

Figure 12. Transatmospheric ascent trajectory starting at $18 \mathrm{~km}$ height and $50 \mathrm{~km}$ downrange from the catapult launch and at $900 \mathrm{~m} / \mathrm{s}$ and GT starting pitch angle of about $65 \mathrm{deg}$.

Transatmospheric speed and thrust-to-weight (T/W) history is shown in Figure 14. The HRBs are used in about 120 seconds and then jettisoned to reduce inert mass. The T/W ratio is linearly increasing with altitude reaching 2.2 at about $135 \mathrm{~km}$ and speed of about 2,250 m/s. We only approximately stitched the transatmospheric and the vacuum ascent regimes as they were calculated separately. The T/W ratio suddenly drops to zero at about $135 \mathrm{~km}$ as that point designated burnout and separation of HRB's and termination of air-breathing ramjet/RBCC propulsion. At that moment VGI is closed and the rocket-mode takes place. Aerodynamic drag plays significant role in transatmospheric flight only up to about 30-40 km as shown in Figure 15. Above $50 \mathrm{~km}$ and speeds in excess of $1,175 \mathrm{~m} / \mathrm{s}$, aerodynamic drag is almost non-existent. Dynamic pressure evolution and max-Q (at $12 \mathrm{~km}$ height) are presented in Figure 16. The max-Q of about $42.5 \mathrm{kPa}$ is quite high due to the fact that Mach 3 is achieved at relatively 
low altitude $(18 \mathrm{~km})$. But the spaceplane is also much more compact and sturdy and does not have long cylindrical bodies that are susceptible to buckling like in traditional multi-stage vertical-launch vehicles. The gravitational loss to achieve about $135 \mathrm{~km}$ height and reach 2,300 m/s from $18 \mathrm{~km}$ and $900 \mathrm{~m} / \mathrm{s}$ while performing GT was numerically integrated to yield $877.3 \mathrm{~m} / \mathrm{s}$. At the same time the aerodynamic loss was only about $30 \mathrm{~m} / \mathrm{s}$. Such low energy losses are primarily the result of choosing high-elevation to begin with.

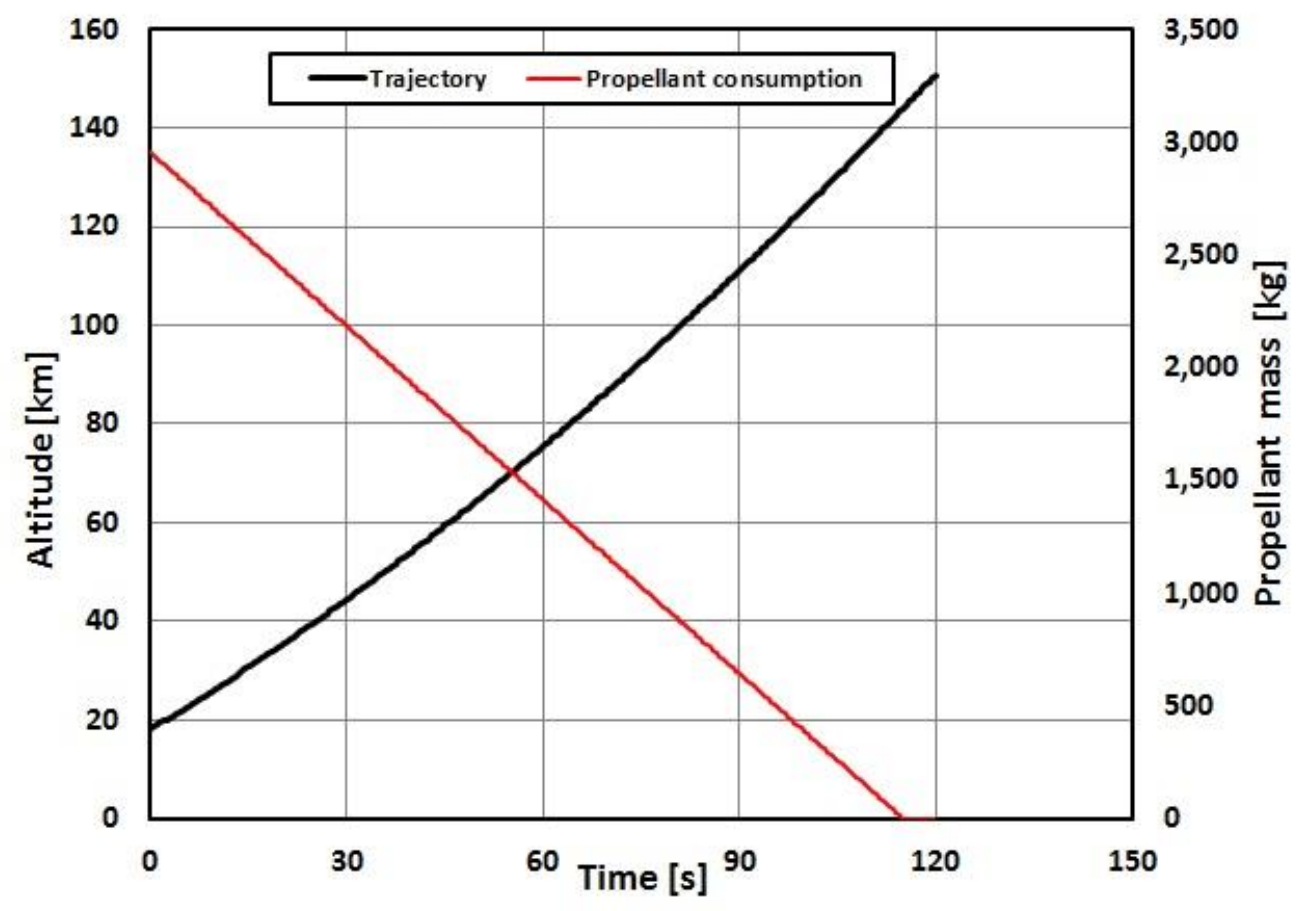

Figure 13. Transatmospheric ascent time and fuel remaining.

The vacuum ascent trajectory and the bi-propellant remaining amount history utilizing rocket-only mode is depicted in Figure 17. Vacuum rocket-only ascent starts at about $130 \mathrm{~km}$ orthometric height and $200 \mathrm{~km}$ downrange from the catapult launch site at $2,300 \mathrm{~m} / \mathrm{s}$ and the GT pitch angle of about 33 degrees to the launch site local horizontal After the separation of HRBs and propellants used for atmospheric propulsion, the spaceplane weighs about 17,000 lb with the LRE proving about $25,000 \mathrm{lbf}(111.206 \mathrm{kN})$ of thrust. The gravity turn started in lower atmosphere continues and is completed by the time the spaceplane reaches about $6,500 \mathrm{~m} / \mathrm{s}$ and $300 \mathrm{~km}$ LEO. Active steering was then performed to maintain desired LEO while accelerating. Simulations showed that $12,000 \mathrm{lb}(5,454 \mathrm{~kg})$ of $\mathrm{LOX} / \mathrm{LH} 2(\mathrm{O} / \mathrm{F}=5: 1)$ for rocket-mode was just sufficient to achieve LEO inertial speed. 


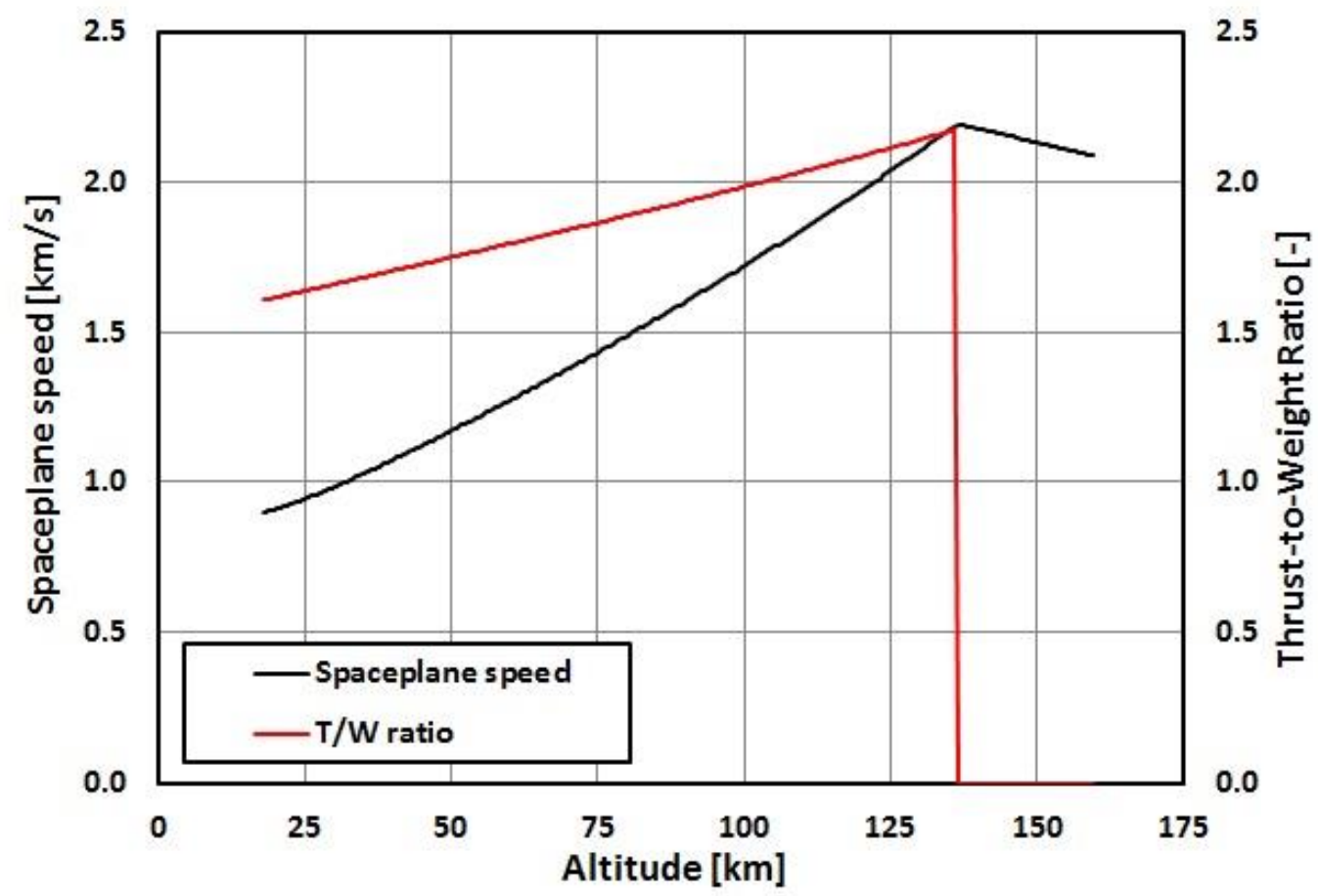

Figure 14. Transatmospheric ascent speed and T/W histories.

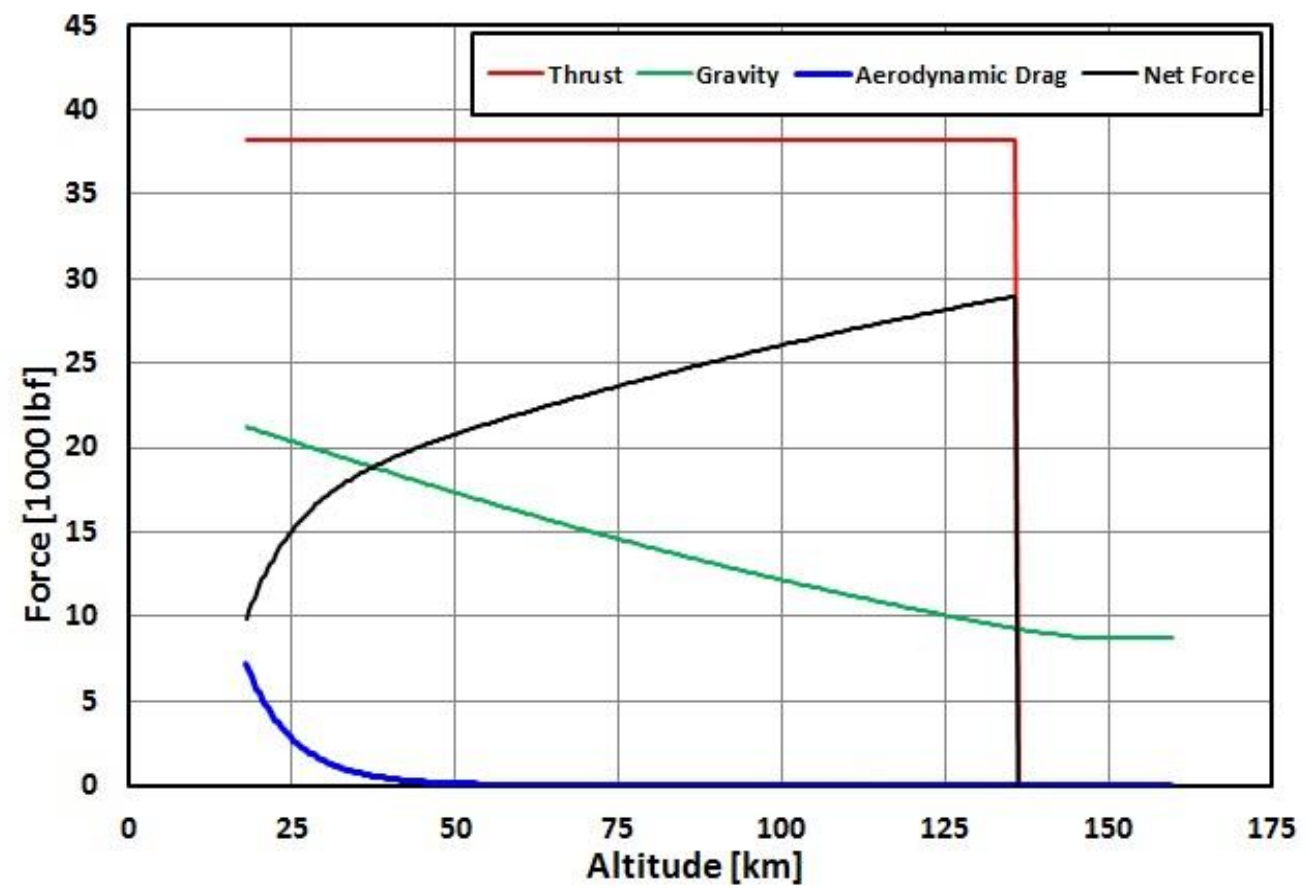

Figure 15. Forces on spaceplane during transatmospheric ascent. 


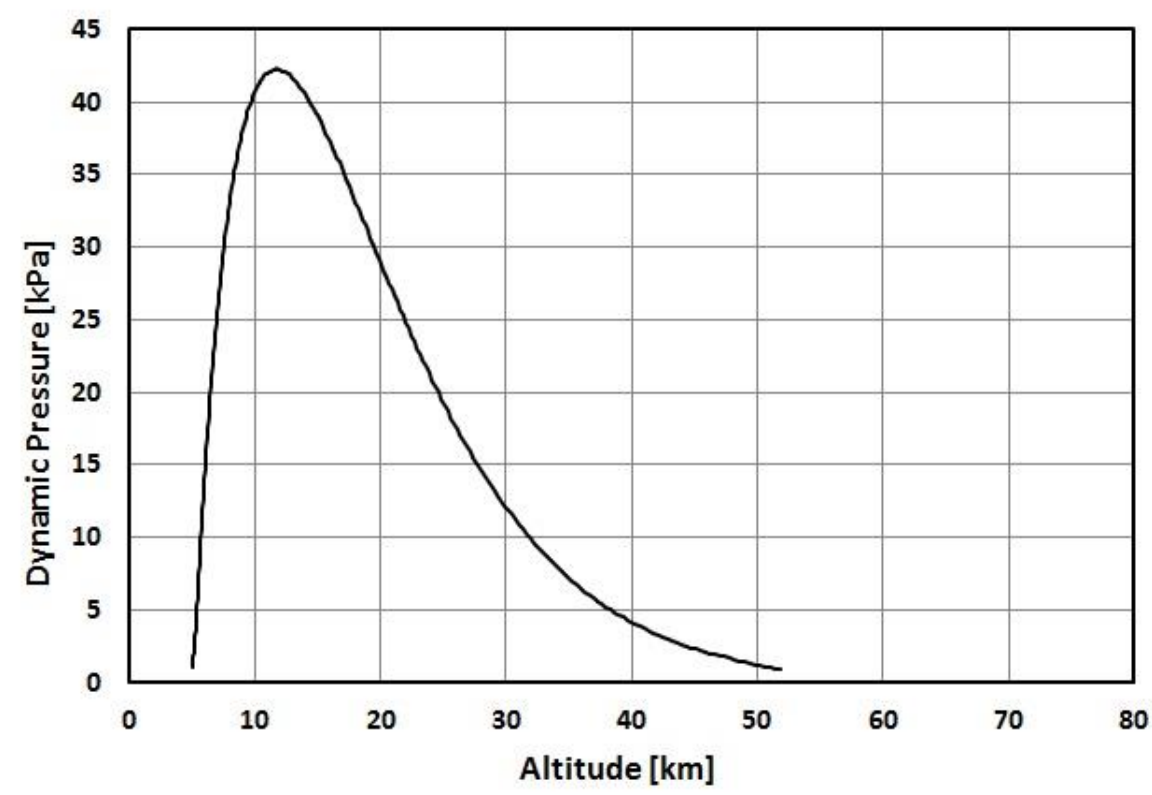

Figure 16. Transatmospheric dynamic pressure (max-Q) history starting from the catapult launch.

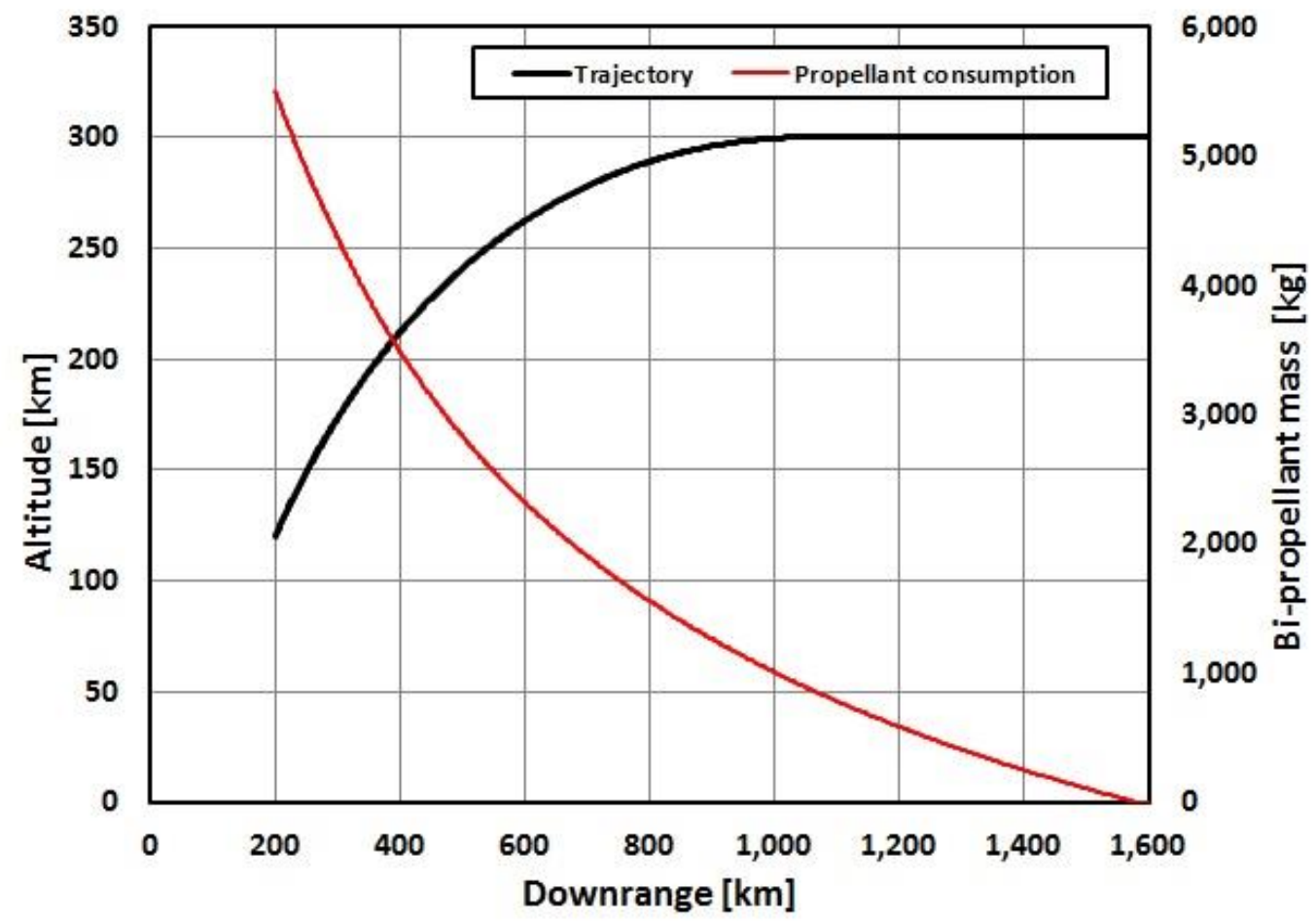

Figure 17. Vacuum ascent trajectory. 
The time history of vacuum ascent is presented in Figure 18. It took about 302 seconds until MECO. This time needs to be added to about 150 seconds of total transatmospheric time-of-flight (TOF) to arrive at the total burnout time of 450 seconds. The simulated spaceplane speed and T/W-ratio history is presented in Figure 19. Thrust-to-weight ratio starts at about 1.5 and is monotonically increased as the propellant is consumed at a constant 25,000 lbf thrust, until T/W of 1.85 is reached. This is the maximum sustained vacuum T/W ratio maintained by throttling down the main LRE. The control and guidance system uses engine gimbals (or other means of thrust-vector-control) to maintain LEO of $300 \mathrm{~km}$ while accelerating to the final orbital speed. Desired circular orbital speed is reached within $\pm 5 \mathrm{~m} / \mathrm{s}$ until cryogenic propellants are used. Simulation of forces acting on the spaceplane in vacuum ascent are presented in Figure 20. Throttling of the LRE sustainer to maintain maximum T/W ratio is obvious.

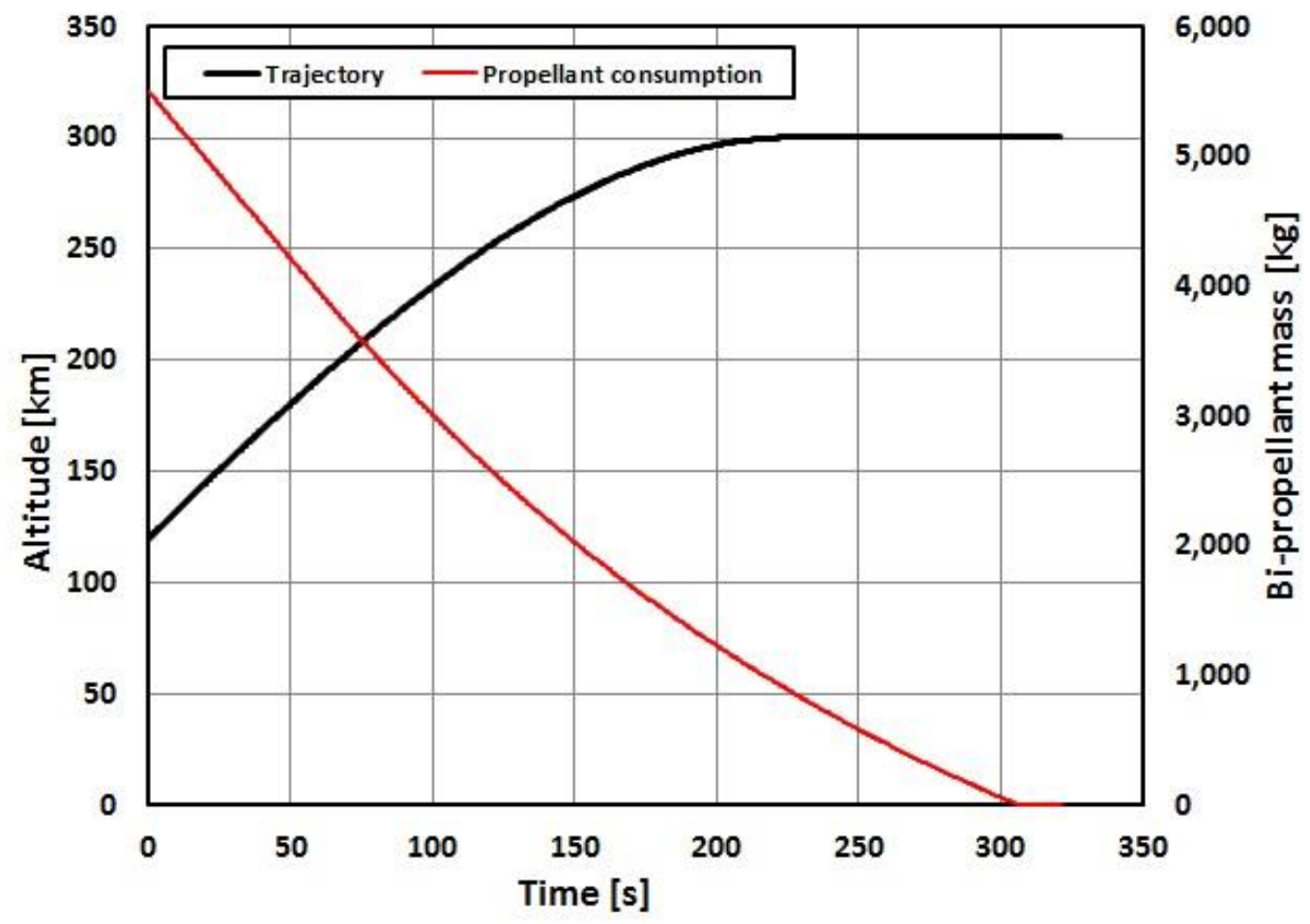

Figure 18. Vacuum ascent time histories.

Numerical integration (Equations C3 in Appendix C) returned the value of $535 \mathrm{~m} / \mathrm{s}$ for the gravity loss during vacuum ascent to LEO. Total gravity loss from 18 to $300 \mathrm{~km}$ is accordingly about 1,400 m/s. Additional gravitational loss exists for the part from the launch site to $18 \mathrm{~km}$ height. 


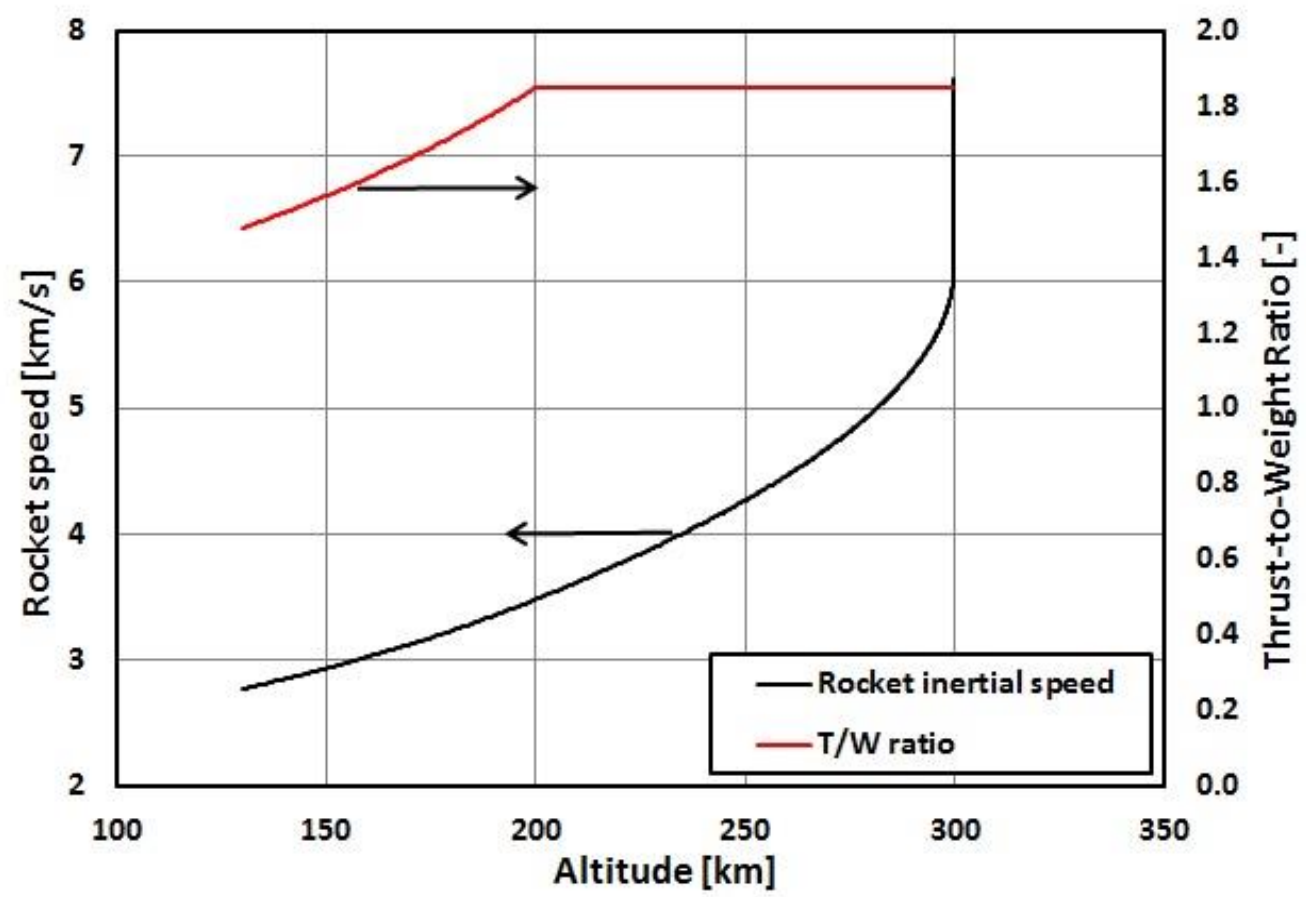

Figure 19. Vacuum ascent speed and T/W histories.

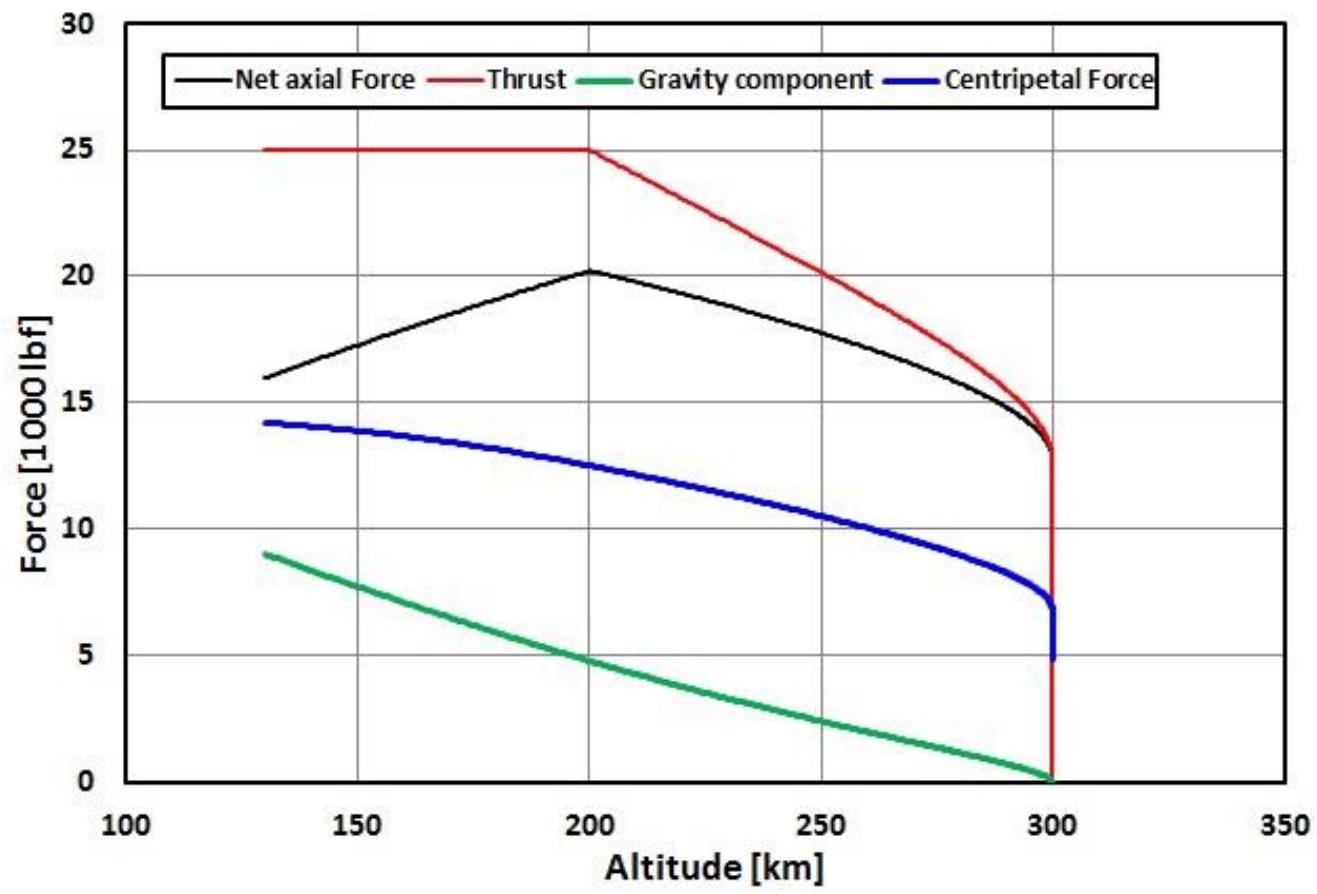

Figure 20. Vacuum ascent forces on spaceplane (drag is negligible at $120+\mathrm{km}$ ). 
The effect of equatorial high-elevation launch site for LEO access is now explored in terms of gravitational loss. In order for a rocket to gain height it must do work against the conservative gravitational field. In the first approximation, the reduction of equatorial acceleration is neglected and spherical Earth with reference acceleration $\mathrm{g}_{0}=9.80665 \mathrm{~m} / \mathrm{s}^{2}$ is assumed. The energy budget due to gravitational field in topocentric frame-of-reference for the vertical zenithdirection can be calculated from the energy balance:

$$
\begin{aligned}
& \frac{(\Delta v)_{g}^{2}}{2}=\int_{R_{L}}^{R_{b}} \vec{F}_{g} \cdot d \vec{r}=\int_{R_{L}}^{R_{b}} \frac{\mu_{E}}{r^{2}} \cdot d r \Rightarrow \Delta v_{g}=\sqrt{\frac{2 \mu_{E}\left(R_{b}-R_{L}\right)}{R_{b}-R_{L}}} \\
& R_{b}=R_{0}+h_{L E O}=6,371+h_{L E O}
\end{aligned}
$$

A specific amount of kinetic energy must be sacrificed to do work against the gravitational field (potential energy gain). It was assumed here that the path is entirely vertical, while in real rocket flight the trajectory will be turning toward the local horizontal.

NASA's Cape Canaveral launch facility (where Kennedy Space Center $\mathrm{KSC}$ is located), is at SL and $\mathrm{N} 28.5^{\circ}$ latitude where we can assume Earth's radius to be approximately equal to its average spherical radius of $6,371 \mathrm{~km}$. This contrasts with the here proposed equatorial launch sites because they are already at the height of about $5 \mathrm{~km}$, plus the Earth's equatorial radius is about $7.1 \mathrm{~km}$ thicker than the average spherical, i.e., 6,378.137 $\mathrm{km}$ (polar radius is 6,356.751 $\mathrm{km}$ ). If we now compare the gravity loss at KSC launch facility with the one at proposed high-equatorial location (about $12 \mathrm{~km}$ less distance to 300-km LEO), we obtain $v_{K S C} / v_{e q}=0.97891$.

For a 300-km LEO spacecraft launched from KSC, the velocity budget required to "defeat" gravity is about $2.37 \mathrm{~km} / \mathrm{s}$, which ultimately results in $50 \mathrm{~m} / \mathrm{s}$ energy savings for launches from the proposed high-elevation equatorial locations. The fact that the local gravitational acceleration is lower at equatorial regions will result in a net gain of about $100 \mathrm{~m} / \mathrm{s}$ which can be added to the 300$310 \mathrm{~m} / \mathrm{s}$ (or eventually even more) gained by catapult launches. Significant savings will also come in reduced aerodynamic drag and steering drag in normally thinner atmosphere at higher elevations. RBCC propulsion further increases average mission specific impulse (reduces required velocity budget for the rocketonly mode), and all these factors combined result in markedly more efficient and cost-effective horizontal ground-based launch method. 
The relative mass ratio (initial-to-final mass) increases exponentially with the velocity ratio (delta-V vs. $C$ ) as a consequence of Equation (1). A simple linear perturbation about the nominal (set) operation point is performed to observe how small changes in delta-V and/or $C$ affect the mass ratio. We can write:

$$
\begin{aligned}
& \frac{M_{i}}{M_{f}}=m r=\exp \left(\frac{\Delta v}{C}\right) \Rightarrow m r=f(\Delta v, C) \\
& \Delta(m r) \approx\left[\frac{\partial(m r)}{\partial(\Delta v)}\right]_{0} \Delta(\Delta v)+\left[\frac{\partial(m r)}{\partial C}\right]_{0} \Delta C \Rightarrow \frac{\Delta(m r)}{(m r)_{0}}=\left(\frac{\Delta v}{C}\right)_{0}\left[\frac{\Delta(\Delta v)}{(\Delta v)_{0}}-\frac{\Delta C}{(C)_{0}}\right]
\end{aligned}
$$

The estimate of the mass-ratio perturbation using the specific impulse instead of the effective exhaust speed, $C=I_{S P} g_{0}$ follows directly from the above Equation (25).

Let us assume that we have the initial speed-ratio of $\Delta v / C=2.2$ and therefore $(m r)_{0}=9.025$. For example, by clever mission design and trajectory optimization we were able to reduce design $\Delta v$ by $5 \%$. Additionally, we were able to increase the effective exhaust speed by $6 \%$ (e.g., from 4,227 to $4,481 \mathrm{~m} / \mathrm{s}$ ) by using more efficient nozzle, improving combustion kinetics, and other small improvements. What is the total change in mass ratio? Since $C=I_{S P} g_{0}$ increased, its effect will be negative, i.e., decreasing the mass ratio $(m r)$. On the other side, reduced design $\Delta v<0$ will have positive effect, or reduce required mass ratio. So the total effect of these small changes will result in;

$$
\frac{\Delta(m r)}{(m r)_{0}}=2.2 \times(-0.05-0.06)=-0.242
$$

Thus, the total initial-to-final mass ratio will be reduced by more than $24 \%$. The mass ratio is a measure of propellant used and it implies that more weight will be available for payload. The payload-to-initial-mass is:

$$
\frac{\Delta\left(m_{P A Y}\right)}{m_{i}}=-\frac{\Delta(m r)}{(m r)_{0}^{2}}=-\frac{1}{(m r)_{0}} \frac{\Delta(m r)}{(m r)_{0}}
$$

Since the mass-ratio is decreasing, the payload-ratio is increasing. But the problem is that in propulsive systems with low IsP, the mass-ratio (conventional chemical rockets) to LEO is significant (in the range from 8 to 10). Thus, the increase in payload-ratio is small for low-ISP propulsion systems. The benefits of 
even small mission-design and propulsion-efficiency improvements are comparatively more significant in the systems with initially higher missionspecific mass-ratios. In our particular case, the payload fraction increased by only about $2.7 \%$ (e.g., payload from $300 \mathrm{~kg}$ to $308 \mathrm{~kg}$ ).

Despite all the technological advances, the SSTO concept remains highly marginal and many experts think that it will never be practical unless high-energy density fuels and efficient RBCC propulsion with mission-average ISP of at least 700 seconds become available. Even though, small performance improvements could be achieved by using high-elevation equatorial catapult-launch locations, it is still not clear if this concept is economically justified. In any case it could work only with high-frequency of launches.

Sure, we can launch payload at large cost. For example, Russian heavy-lift Proton and especially Energia launch vehicles can put up to 200 tons payload in LEO, while ESA's ARIANE $V$ launched from Kourou (French Guiana) can easily put 12 metric tons in geostationary transfer orbit (Maini and Agrawal, 2011). Also USA's vertical-lift launchers such as Atlas, Delta, and Titan have well established reliability record and proven flight heritage. China (Long March series), India (PSLV and GSLV), Japan ( $H-2)$, and other nations are catching up. The main purpose of exploring proposed high-elevation equatorial catapult-launch idea is to achieve an order-of-magnitude lower launch costs compared to existing traditional multistage (parallel and serial) vertical launch systems.

The critical point here are RBCC engines. Some RBCC engines have successfully passed ground testing, but not flight testing and have no flight heritage. Modern composite materials will have to be used to achieve lightweight, yet very strong structures. Efficient and safe catapult launch represents another critical technology. The issue of re-entry thermal loads remains a huge problem. Using the same cooling system as with Space Shuttle Orbiter tiles is prohibitively expensive and time consuming. Additionally, the cryogenic LOX/LH2 bi-propellant remains a bottleneck in achieving space access breakthroughs. While one of the most energetic existing bi-propellants, a mission specific impulse of at least $50 \%$ higher is required for affordable space access. The RBCC concepts could provide some improvements for transatmospheric ascent, but above about $100 \mathrm{~km}$ up to LEO it is full rocket mode again. The search for HED fuels/propellants is ongoing, but that is not going to be an easy endeavor as many such fuels are highly unstable. Catapult could be used to launch spaceplanes horizontally to even greater supersonic speeds (e.g. $500 \mathrm{~m} / \mathrm{s}$ ), but that introduces a number of technical, environmental, and, most of all, safety problems. 
Another possible design improvements would be to use dual-mode ramjet combustion for transatmospheric ascent with RP-1/LOX (ISP of 300 to $360 \mathrm{~s}$ for SL-to-vacuum). It would be used at lower altitudes and airspeeds, followed by LH2/LOX propellants when Mach exceeds 4, or so. The kerosene-like mixture of saturated and unsaturated hydrocarbons (Sutton and Biblarz, 2001) rocket propellant blend RP-1 is about 11.5 times denser than LH2 and thus needs much smaller tanks, which significantly increases density-specific-impulse $I_{\mathrm{dSP}}$ and subsequently reduces aerodynamic drag for transatmospheric ascent. The final spaceplane-RBCC designs would be a compromise between so many opposing factors and the result of complex optimizations.

Even if the proposed idea is reasonable and economically justified, the crucial question is if the respective state governments and local communities would even allow such spaceports to be built. This may be especially sensitive issue in East African countries Kenya and Tanzania which could see disruption of local habitats by proposed spaceports. Suggested spaceports could severely affect local wildlife considering that also access roads have to be built. Considering these factors, special consideration and prioritization must be given to the human, animal, and geographical landscapes if such spaceports are ever to be built.

\section{Conclusions}

A conceptual and feasibility study of an RBCC SSTO catapult-launched strap-on parallel-boosted reusable gliding-reentry spaceplane for economic shortduration manned LEO access is presented and discussed. Several high-elevation equatorial spaceports, each having high-speed catapult-launch mechanisms, adjacent paved runways, and on-site support facilitates to produce propellants and electric energy, are proposed. The proposed multipurpose spaceplane can be used as space-taxi in space tourism and to carry crew and mini satellites. The highelevation equatorial launch sites provide less dense atmosphere, less distance to LEO, and the possibility to launch into any orbital plane. This terrestrial launch system enables direct equatorial LEO's requiring minimum specific energy and delivering maximum specific payload capability of any existing launch system. The use of equatorial catapult launch and high-elevation spaceports in conjunction with RBCC propulsion concept reduces energy requirements by $500-600 \mathrm{~m} / \mathrm{s}$ making it perhaps the most efficient future terrestrial launch system. Additionally, the use of integrated RBCC propulsion engine further increases specific impulse for the portion of transatmospheric flight. Due to the fact that the proposed spaceplane is not large or heavy, the technical, organizational, and safety requirements are much relaxed substantially lowering the operational cost. The first analysis suggests about $\$ 3,000 / \mathrm{kg}$ for payload to LEO. Of course, the fact 
remains that SSTO is highly marginal concept and that RBCC engines still need flight test proving. Without more energetic propellants and very efficient RBCC propulsion devices there seems nothing on the horizon that could make SSTO concept truly practical. The absence of efficient SSTO will continue making access to near space expensive, challenging, and complex. 


\section{Author Bio}

Dr. Nihad E. Daidzic is president of AAR Aerospace Consulting, L.L.C. He is also a full professor of Aviation, adjunct professor of Mechanical Engineering, and a member of the research graduate faculty at Minnesota State University, Mankato. His Ph.D. is in fluid mechanics and his Sc.D. is in mechanical engineering. He conducted the study of the pre-ignition thermal-hydraulic transients in the European Ariane IV $3^{\text {rd }}$ stage cryogenic bi-propellant rocket engine. He was formerly a research associate in applied physics at the Center for Microgravity Research and Applications at Vanderbilt University, and a staff scientist at the National Center for Microgravity Research and the National Center for Space Exploration and Research at NASA Glenn Research Center in Cleveland, OH. He has also held various faculty appointments at Vanderbilt University, University of Kansas, and Kent State University. His current research interest is in theoretical, experimental, and computational fluid dynamics, micro- and nano-fluidics, aircraft/rocket stability, control, and performance, mechanics of flight, piloting techniques, and aerospace propulsion. Dr. Daidzic has "logged" over 1,200 parabolas in NASA's KC-135 microgravity airborne platform, performing various scientific experiments and accumulating many hours of zero, Lunar, and Martian gravity. Dr. Daidzic is a multi-engine airplane Airline Transport Pilot (ATP) and "Gold Seal" CFII/MEI/CFIG with flight experience in airplanes, helicopters, and gliders. 


\section{References}

Ahuja, V., \& Hartfield, R. J. (2012). Combined rocket and scramjet integration for a launch vehicle. 12th AIAA Aviation Technology, Integration, and Operations (ATIO) Conference and 14th AIAA/ISSMO Multidisciplinary Analysis and Optimization Conference, Paper \# AIAA-2012-5560, 17-19 September 2012, Indianapolis, IN, U.S.A. DOI: 10.2514/6.2012-5560

Ashley, H. (1992). Engineering analysis of flight vehicles. New York, NY: Dover.

Balepin, V. (2008). High speed propulsion cycles. Advances on Propulsion Technology for High-Speed Aircraft, Educational Notes RTO-EN-AVT150, Paper \#2, pp. 2-1 - 2-32, Neuilly-sur-Seine, France.

Ball, K. J., \& Osborne, G. F. (1967). Space vehicle dynamics. Oxford, UK: Clarendon Press.

Bate, R. R., Mueller, D. D., \& White, J. E. (1971). Fundamentals of astrodynamics. New York, NY: Dover.

Bertin, J. J., \& Cummings, R. M. (2003). Fifty years of hypersonic: where we've been, where we're going. Prog. Aerospace Sciences, 39(6-7), 511-536. DOI: 10.1016/S0376-0421(03)00079-4

Brooks, C. G., Grimwood, J. M., \& Swenson, L. S. Jr. (2009). Chariots for Apollo: The NASA history of manned lunar spacecraft to 1969. Mineola, NY: Dover.

Carnahan, B., Luther, H. A., \& Wilkes, J. O. (1969). Applied numerical methods, New York, NY: John Wiley \& Sons.

Chapman, D. R. (1958). An approximate analytical method for studying entry into planetary atmospheres (NACA TN-4276). Ames, CA: National Aeronautics and Space Administration.

Chapra, S. C., \& Canale, R. P. (2006). Numerical methods for engineers (5th ed.). Boston, MA: McGraw-Hill.

Chojnacki, K. T. (1992). Rocket based combined cycle (RBCC) propulsion technology (Workshop proceeding executive summary. MSFC, Huntsville, AL.). Washington, D.C.: National Aeronautics and Space Administration. 
Czysz, P. A., \& Richards M. J. (1999). Benefits from incorporation of combined cycle propulsion. Acta Astronautica, 44(7-12), 445-460. DOI: 10.1016/S0094-5765(99)00080-6

Daidzic, N. E. (1990a). LOX dome investigation: Final report. Experimental Program for the Investigation of Pre-Ignition, Transient Flow Behavior in the HM-7B Thrust Chamber, A report prepared for MBB-Aerospace, LSTM 283/I/90, March 1990, Lehrstuhl für Strömungsmechanik, Universität Erlangen-Nürnberg, Germany.

Daidzic, N. E. (1990b). Enlarged injector element pressure drop measurements, Experimental Program for the Investigation of Pre-Ignition, Transient Flow Behavior in the HM-7B Thrust Chamber, $3^{\text {rd }}$ stage engine for the ESA Ariane IV. A report prepared for MBB-Aerospace, LSTM 289/I/90, May 1990, Lehrstuhl für Strömungsmechanik, Universität ErlangenNürnberg, Germany.

Daidzic, N. E. (1991a). Experimental investigation of transient flow in HM-7B $L O X$ dome. Experimental Program for the Investigation of Pre-Ignition, Transient Flow Behavior in the HM-7B Thrust Chamber. A report prepared for MBB-Aerospace, LSTM 310/I/90, February 1991, Lehrstuhl für Strömungsmechanik, Universität Erlangen-Nürnberg, Germany.

Daidzic, N. E. (1991b). Experimental investigation of enlarged injector element $L O X$ post, Experimental Program for the Investigation of Pre-Ignition, Transient Flow Behavior in the HM-7B Thrust Chamber, $3^{\text {rd }}$ stage engine for the ESA Ariane IV. A report prepared for MBB-Aerospace, LSTM 311/I/90, February 1991, Lehrstuhl für Strömungsmechanik, Universität Erlangen-Nürnberg, Germany.

Daidzic, N. E., Popp M., \& Troppa, C. (1991). Transient flow behavior in a rocket engine oxygen dome. 27th Joint AIAA/ASME/SAE Propulsion Conference, Paper \# AIAA-91-2280, June 1991, Sacramento, CA, U.S.A. DOI: $10.2514 / 6.1991-2280$

Daidzic, N. E. (2010) Future hypersonic, suborbital, and orbital travel in business aviation, in: Education Session II of the UAA Conference, October 5-7, 2010, Crowne Plaza, St. Paul, MN, U.S.A.

Daidzic, N. E. (2011, September). Designing propulsion systems for future air/space transportation, Professional Pilot, 45(9), 82-86. 
Daidzic, N. E. (2014, March). Could we colonize Venus? Professional Pilot, Vol. 48, No. 3, pp. 92-96.

Daidzic, N. E. (2015a). Efficient general computational method for estimation of standard atmosphere parameters. International Journal of Aviation Aeronautics, and Aerospace, 2(1), 1-35. DOI: 10.15394/ijaaa.2015.1053

Daidzic, N. E. (2015b). Global optimized isothermal and nonlinear models of Earth's standard atmosphere. International Journal of Aviation Aeronautics, and Aerospace, 2(3), 1-42. DOI: 10.15394/ijaaa.2015.1064

Daidzic, N. E. (2016). Small catapult-assisted horizontal-launch reusable RBCC SSTO spaceplane for economical short-duration LEO access. $\mathrm{A}^{3} \mathrm{IR}$ Aviation Research Conference 2016, Paper \#1209, January 14-17, 2016 Chandler, AZ.

Danby, J. M. A. (1962). Fundamentals of celestial mechanics. New York, NY: The MacMillan Company.

Davies, M. (Ed.) (2003). The standard handbook for aeronautical and astronomical Engineers. New York, NY: McGraw-Hill.

Deutsch, R. (1963). Orbital mechanics of space vehicles. Englewood Cliffs, NJ: Prentice-Hall.

Etkin, B. (1959). Dynamics of flight: Stability and control. New York, NY: John Wiley \& Sons.

Etkin, B. (2000). Dynamics of atmospheric flight. Mineola, NY: Dover.

Farokhi, S. (2009). Aircraft propulsion. Hoboken, NJ: John Wiley \& Sons.

Fitzpatrick, R. (2012). An introduction to celestial mechanics. New York, NY: Cambridge University Press.

Foster, R. W. (1989). Optimization of the rocket mode trajectory in a rocket based combined cycle (RBCC) engine powered SSTO vehicle. 25th Joint Propulsion Conference, Paper \# AIAA-89-2295, Monterey, CA, U.S.A. DOI: $10.2514 / 6.1989-2295$ 
Goddard, R. H. (2002). Rockets (two classical papers: A method of reaching extreme altitudes and liquid-propellant rocket development). Mineola, NY: Dover.

Haidn, O. J. (2008). Advanced rocket engines. Advances on Propulsion Technology for High-Speed Aircraft, Educational Notes RTO-EN-AVT150, Paper \#6, pp. 6-1 - 6-40, Neuilly-sur-Seine, France.

Hammond, W. (1999). Space transportation: A system approach to analysis and design. Reston, VA: American Institute of Aeronautics and Astronautics.

Heiser, W. H., Pratt, D. T., Daley, D. H., \& Mehta, U. B. (1994). Hypersonic airbreathing propulsion. Reston, VA: American Institute of Aeronautics and Astronautics.

Hill, P. G., \& Peterson, C. P. (1992). Mechanics and thermodynamics of propulsion (2nd ed.). Reading, MA: Addison-Wesley.

Huges, P. C. (2004). Spacecraft attitude dynamics. Mineola, NY: Dover.

Humble, R. W., Henry, G. N., \& Larson, W.J. (.ed) (1995). Space propulsion analysis and design. New York, NY: McGraw-Hill.

Huzel, D. K., \& Hwang, D. H. (1992). Modern engineering for design of liquid rocket engines. Reston, VA: American Institute of Aeronautics and Astronautics.

Kanda, T., \& Kudo, K. (2003). Conceptual study of a combined-cycle engine for an aerospace plane. Journal of Propulsion and Power, 19(5), 859-867. DOI: $10.2514 / 2.6176$

Kanda, T., Tani, K., \& Kudo, K. (2007). Conceptual study of a rocket-ramjet combined-cycle engine for an aerospace plane. Journal of Propulsion and Power, 23(2), 301-309. DOI: 10.2514/1.22899

Kloesel, K. J., Ratnayake, N. A., \& Clark C. M. (2011). A technology pathway for airbreathing, combined-cycle, horizontal space launch through SR-71 based trajectory modelling. 17 $7^{\text {th }}$ AIAA International Space Planes and Hypersonic Systems and Technologies Conference, Paper \# AIAA-20112229, April 11-14, 2011, San Francisco, CA. U.S.A. DOI: 10.2514/6.2011-2229 
Kolk, R. W. (1961). Modern flight dynamics. Englewood Cliffs, NJ: PrenticeHall.

Kothari, A. P., Livingston, J. W., Tarpley, C., Raghavan, V., Bowcutt, K. G., \& Smith, T. R. (2011). Rocket based combined cycle hypersonic vehicle design for orbital access. 17 $7^{\text {th }}$ AIAA International Space Planes and Hypersonic Systems and Technologies Conference, Paper \# AIAA-20112338, April 11-14, 2011, San Francisco, CA. U.S.A. DOI: $10.2514 / 6.2011-2338$

Lee, T.-W. (2014). Aerospace propulsion. Chichester, West Sussex, UK: John Wiley \& Sons.

Luetke, N., Mohieldin, T. O., \& Tiwari, S. N. (2007). Numerical optimization study of a rocket based combined cycle. 43rd AIAA/ASME/SAE/ASEE Joint Propulsion Conference \& Exhibit, Paper \# AIAA-2007-5390, July 811, 2007, Cincinnati, OH. U.S.A. DOI: 10.2514/6.2007-5390

Maini, A. K., \& Agrawal, V. (2011). Satellite technology: Principles and applications (2nd ed.). Chichester, West Sussex, UK: John Wiley \& Sons.

Manski, D., Goertz, C., Saßnick, H.-D., Hulka, J. R., Goracke, B. D., \& Levack, D. J. H. (1998). Cycles for Earth-to-orbit propulsion. Journal of Propulsion and Power, 14(5). 588-604. DOI: 10.2514/2.5351

Moulton, R. F. (1970). An introduction to celestial mechanics. New York, NY: Dover.

Oates, G. C. (1997). Aerothermodynamics of gas turbine and rocket propulsion (3rd ed). Reston, VA: American Institute of Aeronautics and Astronautics.

Olds, J., \& Walberg, G. (1993). Multidisciplinary design of a rocket-based combined-cycle SSTO launch vehicle using Taguchi method. AIAA/AHS/ASEE Aerospace design conference, Paper \# AIAA-93-1096, February, 16-19, 1993, Irvine, CA. U.S.A.

Olds, J., \& Bellini, P. X. (1998). Argus, a highly reusable SSTO rocket-based combined cycle launch vehicle with Maglifter launch assist. 8th AIAA International Space Planes and Hypersonic Systems and Technology Conference, Paper \# AIAA-98-1557, February, 16-19, 1993, Norfolk, VA. U.S.A. DOI: $10.2514 / 6.1998-1557$ 
Plummer, H. C. (1960). An introductory treatise on dynamical astronomy. New York, NY: Dover.

Press, W. H, Teulkolsky, S. A., Vetterling, W. T., \& Flannery, B. P. (1992). Numerical recipes in FORTRAN: The art of scientific computing (2nd ed.). Cambridge, UK: University Press.

Regan, F. J., \& Anandakrishnan S. M. (1993). Dynamics of atmospheric re-entry. Reston, VA: American Institute of Aeronautics and Astronautics (AIAA).

Sellers, J. J. (2005). Understanding space: An introduction to astronautics (3rd ed.). New York, NY: McGraw-Hill.

Shevell, R. S. (1983). Fundamentals of flight. Englewood Cliffs, NJ: PrenticeHall.

Smith, T. D., Steffen, C. J. Jr., Yungster, S., \& Keller, D. J. (1998). Performance of an axisymmetric rocket based combined cycle engine during rocket only operation using linear regression analysis (NASA Report TM-1998206632). Washington, D.C.: National Aeronautics and Space Administration.

Stacey, F. D., \& Davis, P. M. (2008). Physics of the earth (4th ed.). Cambridge, UK: Cambridge University Press.

Sutton, G. P., \& Biblarz, O. (2001). Rocket propulsion elements (7th ed.). New York, NY: John Wiley \& Sons.

Sutton, G. P. (2006). History of liquid propellant rocket engines, Reston, VA: American Institute of Aeronautics and Astronautics (AIAA).

Tewari, A. (2007). Atmospheric and space flight dynamics, Boston, MA: Birkhäuser.

Thomson, W. T. (1986). Introduction to space dynamics, New York, NY: Dover.

Tsohas, J., Appel, B., Rettenmaier, A., Walker, M., \& Heister, S. D. (2009). Development and launch of the Purdue hybrid rocket technology demonstrator. 45th AIAA/ASME/SAE/ASEE Joint Propulsion Conference \& Exhibit, Paper \# AIAA 2009-4842, 2-5 August 2009, Denver, Colorado. DOI: 10.2514/6.2009-4842 
Vinh, N. X. (1993). Flight mechanics of high-performance aircraft. Cambridge, UK: Cambridge University Press.

Ward, T. A. (2010). Aerospace propulsion systems. Singapore, Singapore: John Wiley \& Sons.

Weiland, C. (2010). Computational space flight mechanics. Berlin, Germany: Springer.

Zaehringer, A. J. (2004). Rocket science: Rocket science in the $2^{\text {nd }}$ millennium. Burlington, Canada: Apogee books. 


\section{Appendix A}

\section{Rocket engine thrust computations}

The actual thrust produced by the rocket-engine alone is:

$$
T_{\text {eff }}=\lambda \dot{m}_{\text {prop }} C=\lambda\left[\dot{m}_{\text {prop }} v_{e}+\left(p_{e}-p_{a}\right) A_{e}\right]=\lambda \dot{m}_{\text {prop }} c^{*} C_{F}
$$

The one-dimensional flow nozzle efficiency $\lambda$ accounts for various losses and is typically in the range of 0.85 to 0.98 (Hill and Peterson, 1992; Humble et al., 1995; Sutton and Biblarz, 2001). We assumed optimistic value of 0.975 . While some parameters, such as thrust coefficient $\mathrm{C}_{\mathrm{F}}$, are changing as a function of atmospheric pressure, thrust or T/W (and acceleration) may be kept constant simply by throttling action modulating the propellant flow, which is relatively simple in the case of LRE. The effective (net) specific impulse and thrust are:

$$
I_{S P}^{e f f}=\frac{\lambda c^{*} C_{F}}{g_{0}} \quad T(t)=\lambda c^{*} C_{F} \dot{m}_{\text {prop }}(t)=I_{S P}^{e f f} g_{0} \dot{m}_{\text {prop }}(t)
$$

The expanded equation to calculate the specific impulse is:

$$
I_{S P}^{e f f}=\frac{\lambda \cdot c^{*}}{g_{0}}\left\{\sqrt{\left(\frac{2 \gamma^{2}}{\gamma-1}\right) \cdot\left(\frac{2}{\gamma+1}\right)^{\frac{\gamma+1}{\gamma-1}}\left[1-\left(\frac{p_{e}}{p_{0}}\right)^{\frac{\gamma-1}{\gamma}}\right]}+\varepsilon \cdot\left(\frac{p_{e}-p_{a}}{p_{0}}\right)\right\}
$$

The thrust coefficient is (Humble et al., 1995):

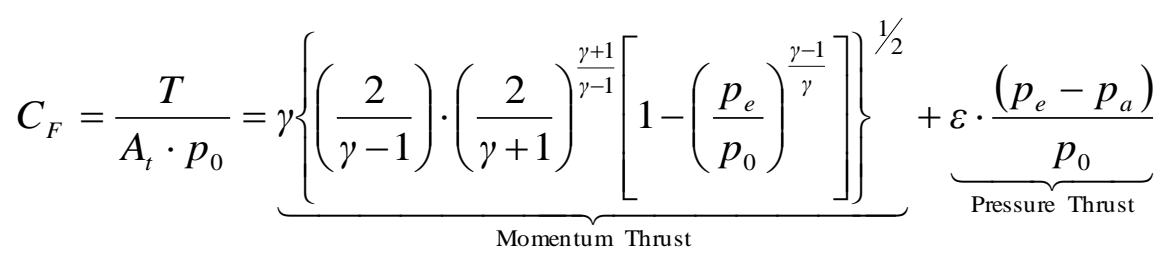

The ideal thrust-coefficient exists when the nozzle exit pressure is equal to the ambient pressure $\left(p_{e}=p_{a}\right)$. The characteristic chamber combustion speed is (Hill and Peterson, 1992; Humble et al., 1995): 


$$
c^{*}=\frac{A_{t} \cdot p_{0}}{\dot{m}_{\text {prop }}}=\frac{\eta_{c} \sqrt{\gamma R T_{0}}}{\gamma\left(\frac{2}{\gamma+1}\right)^{\frac{\gamma+1}{2(\gamma-1)}}}=\frac{a_{0}}{\Gamma} \quad \gamma=\frac{c_{p}}{c_{v}} \quad R=\frac{8,314.32}{M}
$$

For example, in the case of the bi-propellant LOX/LH2 mixture with the combustion chamber absolute temperature of $T_{0}=2800 \mathrm{~K}$, combustor pressure of $p_{0}=30 \mathrm{bar}(3 \mathrm{MPa})$, oxidizer-to-fuel $(O / F=3.6)$, the molecular weight of combustion products $M=9.5$, isentropic coefficient $\gamma=1.26$, and the combustion efficiency $\eta_{c}=97 \%$, the characteristic speed becomes about $c^{*}=2,301.0 \mathrm{~m} / \mathrm{s}$. If the expansion ratio is set then we can calculate the nozzle exit Mach number (we want to maximize it), according to:

$$
\varepsilon=\frac{A_{e}}{A_{t}}=\frac{1}{M_{e}}\left[\left(\frac{2}{\gamma+1}\right)\left(1+\frac{\gamma-1}{2} M_{e}^{2}\right)\right]^{\frac{\gamma+1}{2(\gamma-1)}}
$$

Numerical methods were used to solve this nonlinear implicit equation for unknown nozzle exit Mach number. Once we find the nozzle exit averaged Mach number for given propellants and assumed nozzle expansion ratio, we can calculate the ratio of the exit and combustion pressures:

$$
\frac{p_{e}}{p_{0}}=\left(1+\frac{\gamma-1}{2} M_{e}^{2}\right)^{\frac{\gamma}{1-\gamma}} \Rightarrow M_{e}=\sqrt{\frac{2}{\gamma-1}\left[\left(\frac{p_{e}}{p_{0}}\right)^{\frac{1-\gamma}{\gamma}}-1\right]}
$$




\section{Appendix B}

Analytical solution of gravity turn vacuum ascent trajectory

The angle between the velocity vector and the local vertical $\varphi=\pi / 2-\theta$ (zenith direction) in topocentric frame (see Figure 9), which changes from the initial condition value (e.g., almost vertical to local horizontal or $90^{\circ}$ ) is used (Thomson, 1986). Neglecting aerodynamic drag is fair assumption at higher altitudes (above $60 \mathrm{~km})$ :

$$
\begin{aligned}
& \frac{1}{g} \frac{d v}{d t}=\frac{1}{g} \frac{T}{m}-\cos \varphi \\
& \frac{v}{g} \frac{d \varphi}{d t}=\sin \varphi \\
& \frac{d y}{d t}=v \cos \varphi \\
& \frac{d x}{d t}=v \sin \varphi
\end{aligned}
$$

The analytical solution of the above set of nonlinear ODE is only possible if constant T/W and gravitational acceleration is assumed resulting in (Thomson, 1986):

$$
v=C z^{n-1}\left(1+z^{2}\right) \quad C=\frac{v_{0}}{z_{0}^{n-1}\left(1+z_{0}^{2}\right)}
$$

Where index " 0 " signifies initial condition (vertical height and speed) and:

$$
z=\tan \left(\frac{\varphi}{2}\right) \quad n=\frac{T}{m g}=\frac{T}{W}=\text { const }
$$

The time history can be evaluated from (Thomson, 1986):

$$
t=\frac{C}{g}\left[z^{n-1}\left(\frac{1}{n-1}+\frac{z^{2}}{n+1}\right)-z_{0}^{n-1}\left(\frac{1}{n-1}+\frac{z_{0}^{2}}{n+1}\right)\right]
$$




\section{Appendix C}

Simple numerical algorithm for rocket ascent trajectory simulations

A numerical method based on a fixed forward-time (FT), single-step, Euler marching-in-time solver (Carnahan et al., 1969; Chapra and Canale, 2006; Press et al., 1992) is presented. This simple procedure can be easily programmed, and still yield reasonably accurate results for the flight durations used. The time step used here is 0.5 seconds. The set of discretized ODE using single-step, FT, explicit Euler numerical integration $(n=0,1,2, \ldots, N)$, yields:

$$
\begin{aligned}
& v^{n+1}=v^{n}+\left(\frac{T^{n}}{m^{n}}\right) \Delta t-\left[g\left(h^{n}\right) \cdot \sin \left(\theta^{n}\right)\right] \Delta t-\frac{\rho^{n}}{2 B C^{n}}\left(v^{n}\right)^{2} \Delta t \\
& \theta^{n+1}=\theta^{n}+\Delta \theta\left(h^{n}\right) \quad \Delta \theta\left(h^{n}\right)=\left\{\begin{array}{cc}
0 & h_{0} \leq h \leq h_{G T} \\
-\frac{g\left(h^{n}\right) \cdot \cos \left(\theta^{n}\right)}{v^{n}} & h_{G T}<h \leq h_{L E O}
\end{array}\right\} \\
& m^{n+1}=m^{n}-\dot{m}_{\text {prop }}\left(h^{n}\right) \cdot \Delta t \\
& m_{\text {prop }}^{n+1}=m_{\text {prop }}^{n}+\dot{m}_{\text {prop }}\left(h^{n}\right) \cdot \Delta t \\
& h^{n+1}=h^{n}+v^{n} \sin \left(\theta^{n}\right) \Delta t \\
& x^{n+1}=x^{n}+v^{n} \cos \left(\theta^{n}\right) \Delta t
\end{aligned}
$$

with:

$$
g^{n}=g_{e}\left(\frac{R_{0}}{R_{0}+h^{n}}\right)^{2} \quad \rho^{n}=\rho_{0} \cdot \exp \left[-\frac{g^{n} \cdot h^{n}}{R_{A I R} \cdot T_{0}}\right] \quad B C^{n}=\frac{m^{n}}{C_{D} A}
$$

For example, the ICs for one of several tested discretized models of vacuum propulsion and orbit injection are:

$v_{0}=2,300 \mathrm{~m} / \mathrm{s} \quad \theta^{0}=\theta_{0} \quad m_{0}=m_{i} \quad h^{0}=120 \mathrm{~km} \quad x^{0}=200 \mathrm{~km}$

We can, for all practical purposes, neglect aerodynamic drag for nearly vacuum ascent. The final (burnout) mass of the spaceplane is the initial mass minus the propellant used for ascending in trans-atmospheric flight:

$m_{b}=m_{f}=m^{N}=m_{i}-m_{\text {prop }}^{N}=m_{0}-m_{\text {prop }}^{N}$ 
The integration process also enabled a calculation of design, gravity loss, and aerodynamic-drag loss equivalent to delta- $v$ or $\Delta v$ (see Equations 6 and 16):

$$
\Delta v_{\text {design }}=\Delta t \cdot \sum_{i=1}^{N} \frac{T_{i}}{m_{i}} \quad \Delta v_{g}=\Delta t \cdot \sum_{i=1}^{N} g\left(h_{i}\right) \cdot \sin \left(\theta_{i}\right) \quad \Delta v_{D}=\Delta t \cdot \sum_{i=1}^{N} \frac{D_{i}}{m_{i}}
$$

